\title{
Cost-effectiveness Analysis of Per-abdominal and Laparoscopic Cholecystectomy
}

\author{
Author: \\ ISLAM, MD SHAHARIAR \\ National Institute of Preventive \& Social Medicine (NIPSOM), Bangladesh \\ E-Mail: dr_s_islam@yahoo.com \\ MPH (Health Promotion \& Health Education), NIPSOM
}




\section{Abstract}

Cholelithiasis is one of the major problems which need cholecystectomy. Laparoscopic cholecystectomy is a newer technique. But there is a need to evaluate the cost-effectiveness of per-abdominal and laparoscopic method from patients' perspective. The study was performed to assess the cost-effectiveness of perabdominal and laparoscopic cholecystectomy. sectional study in two sample situations was conducted among 90 purposively selected cholecystectomy patients of which 60 patients underwent laparoscopic cholecystectomy (LC) and 30 patients underwent per-abdominal cholecystectomy (PAC) from three tertiary level government hospitals of Dhaka, Bangladesh at the time of their discharge through face to face interview using a semi-structured questionnaire and checklist. The study found average age $45.33( \pm 13.63)$ and $41.75( \pm 13.39)$ years in PAC and LC respectively. Average monthly income was less in the PAC group Tk.23200.00 $( \pm 12374.61)$ than LC Tk.24925.00( \pm 12166.86$)$. Average duration of suffering from cholelithiasis was $9.50( \pm 8.68)$ months in PAC group and $12.43( \pm 17.49)$ months in LC group. Average hospital stay was $13.97( \pm 6.88)$ days in PAC group while it was $12.02( \pm 6.66)$ days in LC group. Average treatment cost was little higher Tk.21927.40 \pm 7795.89 in LC group than Tk.21466.30 \pm 6261.42 in the PAC group. Both direct cost and indirect cost were also

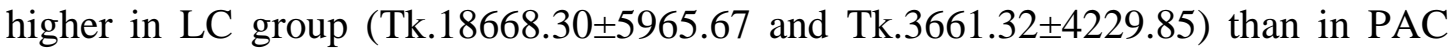

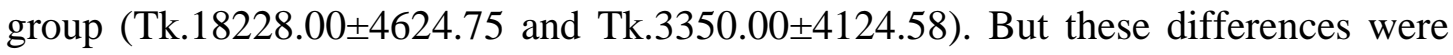
not statistically significant. In both groups treatment cost significantly increased with duration of hospitalization (correlation, $\mathrm{p}<0.01$ ). Cure rate was significantly high in LC group (94.4\%) than in PAC group $(86.7 \%)\left(\chi^{2}, \mathrm{p}<0.05\right)$. method is cost-effective than PAC method. Total treatment cost in LC can be reduced by minimizing hospital cost, laboratory cost and securing the income of the patients which enhance the economic load.

Keywords: cholelithiasis; cholecystectomy; direct cost; indirect cost; laparoscopic cholecystectomy; per-abdominal cholecystectomy 


\section{Introduction}

Cholelithiasis is the commonest biliary tract disorder demanding surgical intervention. Cholecystectomy is the surgical procedure to remove gallbladder due to cholelithiasis with or without pain. It can be done either per-abdominal or laparoscopy method. A laparoscopic cholecystectomy is less invasive. The recovery time is usually shorter in laparoscopy than per-abdominal surgery. In some cases the laparoscope may show that gallbladder is very diseased or it may show other problems. Then the surgeon may have to use per-abdominal method to remove gallbladder safely (Luschka, H.V. et al., 2008).

First cholecystectomy was performed in 1887 , and then there was no dramatic change in surgical approach to gallstone disease for almost 100 years. Laparoscopic cholecystectomy has revolutionized the treatment of gall stone disease, being an important innovation of the 20th century and has become in recent years the standard approach for managing symptomatic cholelithiasis (Soper, N.J. et al., 1992). With improvements in anesthesia and preoperative care laparoscopic cholecystectomy (LC) was attempted as an outpatient cost-effective procedure compared to per-abdominal approach, despite several concerns about patient safety which initially halted its worldwide acceptance (Wenner, D.E. et al., 2006).

Laparoscopic approach has different set of outcomes as compared to per-abdominal technique. Laparoscopic cholecystectomy replacing per-abdominal cholecystectomy as the standard surgical approach for cholelithiasis in developed countries, including rural areas. In contrast, there were initially many controversies in developing countries regarding the laparoscopic techniques, mainly due to the high costs and resources required (Manning, R.G. et al., 2009). Laparoscopic cholecystectomy has become standard practice for benign gallbladder disease (Harrison, E.M. et al., 2012). By using smaller incisions, the laparoscopic approach results in improved cosmetic outcome, reduced postoperative pain, and quicker recovery for many patients (Tiwari, M.M. et al., 2011).

The costs of both procedures were still a subject of controversy as to the clinical benefits. Only few studies have placed their emphasis on comparing costs. The costs of per-abdominal cholecystectomy have ranged from US\$2,221 to US\$9,857, with a mean value of about US\$ 4,953. The financial cost per surgery was higher in laparoscopic cgolecystectomy group than in per-abdominal cholecystectomy group 
(Medeiros, A.C. et al., 2012).

Mean cost of treatment was significantly higher in the per-abdominal group compared to laparoscopic group. Another study found laparoscopic cholecystectomy to be more cost effective (Solanki, K. et al., 2010). The variability in cost-effectiveness in different studies might be attributed to difference in structure of indirect costs include factors such as, per day bed cost of hospital, cost of absenteeism from occupation, cost of attendant and caregivers and cost of post-operative medication. These costs vary substantially in different environments. (Shukla, A. et al., 2017).

Laparoscopic cholecystectomy is now the first-line treatment for uncomplicated gallstone disease in high-income countries and is associated with shorter hospital stays, reduced morbidity, more rapid return to work, lower mortality and significantly reduced hospital costs compared to per-abdominal technique (Ray-Offor, E. et al., 2014). The practice of laparoscopy in low and middle income countries (LMICs) remains limited (Topcu et al., 2002). Economic and cost-effectiveness concerns are frequently cited as major barriers to widespread acceptance of laparoscopic surgery (Ray-Offor, E. et al., 2014). Despite such uncertainty regarding the value of laparoscopy in LMICs, studies have repeatedly demonstrated that minimally invasive surgery is safe, feasible, and beneficial in low-resource settings (Price, R. et al., 2013).

However, there are certain pitfalls of laparoscopic cholecystectomy. Threedimensional depth perception is limited by the two-dimensional monocular image. It is more difficult to control significant hemorrhage in the surgical field (Choy, I. et al., 2013). There is less discrimination of structures using laparoscopic instruments as compared to direct digital palpation during per-abdominal cholecystectomy (Lundberg, O. et al., 2001). A number of studies have reported that laparoscopic cholecystectomy takes a longer time to complete than per-abdominal surgery (Pessaux, P. et al., 2001).

A study found that frequency of postoperative complications was relatively high in per-abdominal group $50.5 \%$ as compared to laparoscopic group (37\%). Average hospital stay was shorter in laparoscopic group as compared to per-abdominal. Return to normal work was also significantly shorter in laparoscopic cholecystectomy group as compared to per-abdominal cholecystectomy group (Talpur, K.A.H. et al., 2011). 
In 2015, The Lancet Commission on Global Surgery estimated that five billion people lack access to safe, affordable surgical and anesthesia care when needed (Meara, J.G. et al., 2015), (Alkire, B.C. et al., 2015). Further, essential surgical and anesthesia care was established as cost-effective interventions in low-resource settings (Chao, T.E. et al., 2014). However, 81 million individuals face catastrophic health expenditures due to payment for both surgery and anesthesia, and the non-medical costs associated with accessing surgical care (Shrime, M.G. et al., 2015).

Determining the most cost-effective option is the key to ensure that limited resources are best used to combat the unmet need of surgical care. For strong evidence supporting the safety and feasibility of laparoscopy in low and middle income countries and the continual lack of uptake of laparoscopic surgery, there is a need to determine the value of laparoscopic cholecystectomy in comparison with perabdominal approach. The purpose of this study was to estimate the cost effectiveness of per-abdominal and laparoscopic cholecystectomy.

With this knowledge of advantages and disadvantages of laparoscopic cholecystectomy and per-abdominal cholecystectomy in symptomatic cholelithiasis, further studies are necessary to provide conclusion as to which method is cost effective and provides better patient satisfaction. The present study was carried out for this very purpose. Aim of the study was to assess cost-effectiveness of per-abdominal and laparoscopic cholecystectomy in adult cholelithiasis patient in respect to patient cured.

\section{Justification}

Cholelithiasis is the commonest biliary pathology affecting females predominantly all over the world (Conlon, K., 2008). The prevalence of gallstones in females of western countries is about twice to that of males (Cuschieri, A.S., 2002). Cholecystectomy, either per-abdominal or laparoscopic is one of the common operations performed in surgery all over the world. Laparoscopic cholecystectomy has now surpassed the perabdominal approach as the standard operation due to significant decreases in operative time, patient pain, hospital stay, and costs in developed country (Keus, F. et al., 2006).

Since the introduction of laparoscopy into general practice, the surgical treatment of gallstones is changed and therefore elective laparoscopic cholecystectomy has almost 
replaced the per-abdominal procedure (Johansson, M. et al., 2005). At present, approximately one million laparoscopic cholecystectomies are performed annually in the United States. Ninety-six percent of all cholecystectomies are performed in a minimally invasive fashion (Tsui et al., 2013).

In this series there is no significant difference in complications between laparoscopic and per-abdominal cholecystectomy. But study showed that frequency of complications was $13.5 \%$ for per-abdominal cholecystectomy and $6.4 \%$ for laparoscopic cholecystectomy (Fajardo, R. et al., 2011). In this study total cost of laparoscopic surgery is less than per-abdominal surgery though operation team charge is more in laparoscopic surgery. This is due to increase hospital stay and increase medication cost for per-abdominal surgery. (Rahman, M.S. et al., 2016)

Literature showed that the average cost of laparoscopic cholecystectomy was lower than per-abdominal cholecystectomy and laparoscopic cholecystectomy was more cost-effective than per-abdominal cholecystectomy (Fajardo, R. et al., 2011). In another study, the cost of the laparoscopic procedure was higher than that for perabdominal surgery (El-Fellah, N. et al., 2011).

Minimally invasive approaches have both revolutionized the treatment of patients with gallstone disease for the better and changed the profile of cholecystectomy. On the whole, undergoing laparoscopic cholecystectomy patients now tend to be younger and healthier, whereas per-abdominal cholecystectomy tend to be older and less well, and per-abdominal operation is often performed in higher-risk, complicated scenarios (Khan et al., 2007).

Laparoscopic cholecystectomy is widely used method in high income countries where as till today it is not widely accepted and used method in low and middle income countries like Bangladesh, where still per-abdominal cholecystectomy is more preferable. About $70-80 \%$ of cholecystectomies are done laparoscopically (Livingstone, E.H. et al., 2004) where as 20-30\% are still completed by perabdominal cholecystectomy (Ros, A. et al., 2006). Mean postoperative hospital stay for laparoscopic surgery was 3.5 days and in per-abdominal cholecystectomy was 6 days. In this study total cost of laparoscopic surgery is less than per-abdominal surgery though operation team charge is more in laparoscopic surgery (Rahman, M.S. et al., 2016). 
By laparoscopic method the gallbladder is removed through four small incisions. So, cosmetic advantages of laparoscopic cholecystectomy are obvious. Although the effectiveness of this technique has been suggested by several studies, the numbers of clinical trials comparing laparoscopic cholecystectomy with the traditional perabdominal cholecystectomy are sparse. Since its introduction, laparoscopic cholecystectomy has been performed with increasing frequency. Many studies have documented that laparoscopic cholecystectomy is associated with less postoperative pain, a shorter hospital stay, and a more rapid recovery and return to normal activity than per-abdominal cholecystectomy (Stoker, M.E. et al., 1992).

The efficiency and safety of any new medical procedure, however, should be established by comparing it with the currently available and generally accepted technique. Symptomatic cholelithiasis has been treated by per-abdominal cholecystectomy with excellent results for more than hundred years. The currently acceptable mortality rate $(0.2 \%)$ and complication rates $(3 \%-5 \%)$ for selective perabdominal cholecystectomy are quite low (Morgenstern, L. et al., 1992).

There is wide variation in costs, for the same operation performed in different hospitals. Several studies have compared the cost-effectiveness of laparoscopic compared to per-abdominal surgery. These studies, however, concentrate on the costs of prolonged operation times and decreased hospital stay. A limited number of studies have examined, in detail, the comparative costs of one operation comparing use of disposable against re-usable laparoscopic equipment or with a large number of consecutive cases (Demoulin, L. et al., 1996).

Previous studies indicate mixed results regarding whether or not implementation of laparoscopy is cost-effective in low-resource settings (Bailey, H.H. et al., 2005). While others suggest that economic benefit may only be for higher-income patients until future cost reduction strategies can be employed. Health resources in most of the developing countries are very limited with around 5\% of GDP being spent on healthcare (Peters, D.H. et al., 2002).

In Bangladesh perspective this type of study is limited where comparison of perabdominal and laparoscopic cholecystectomy was done. A study conducted in a private hospital of Bangladesh which showed that operation team charge is more in laparoscopic cholecystectomy, but total cost is more in per-abdominal cholecystectomy. This difference was due to post-operative morbidity and 
hospitalization (Rahman, M.S. et al., 2016).

To ensure need based health care irrespective of economic hardship it was rational to conduct cost effectiveness analysis of per-abdominal and laparoscopic cholecystectomy. It would be an important consideration in low- and middle-income countries like Bangladesh which yet not discovered as because this type of study was very scarce. This study was done to assess the cost-effectiveness between laparoscopic and per-abdominal cholecystectomy in government hospital settings from patients perspective which might create the way to overcome the economic constraints in these settings.

\section{Research Hypothesis}

Laparoscopic cholecystectomy is cost-effective than per-abdominal cholecystectomy.

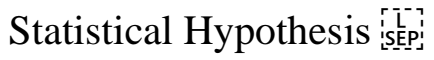

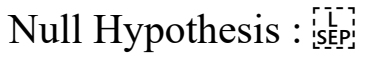

Per-abdominal cholecystectomy is cost-effective than laparoscopic cholecystectomy.

\section{Alternative Hypothesis :}

is cholecystectomy is cost-effective than per-abdominal cholecystectomy.

\section{Research Objectives}

\section{General Objectives :}

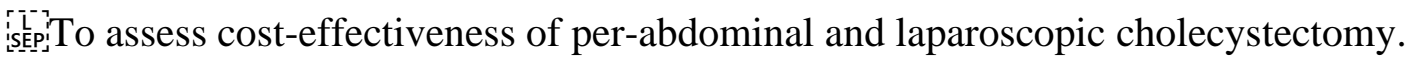

\section{Specific Objectives :}

To estimate costs (direct and indirect) of both per-abdominal and laparoscopic istepicholecystectomy incurred by the patients. istepi]

To determine the clinical outcome of both per-abdominal and laparoscopic is ípericholecystectomy. 
To compare cost per unit of benefit (patient cured) between perabdominal and iscepilaparoscopic cholecystectomy.

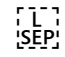

$\square$ To determine the socio-demographic characteristics of the patients.

\section{List of Key Variables}

Variables related to type of cholecystectomy:

Laparoscopic cholecystectomy.

Per-abdominal cholecystectomy.

\section{Variables related to outcome of cholecystectomy:}

Cured.

Complicationsis

Intra-operative complication-Injury.

$\square$ Post-operative complications-Infection.

\section{Variables related to cost:}

\section{Direct costs:}

o Consultation fee

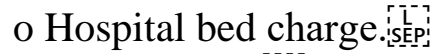

o Cost of drug. [íc]'

o Cost of laboratory investigation.

o Travel cost.

o Cost of foods. 'SEEP

o Cost of attendant. [i] [i]p]

o Tips for treatment.

$\square$ Indirect costs: $:\left[{ }^{i}\left[-p^{i}\right]\right.$

o Loss of income

o Family costistepin

o Unofficial payment.

Variables related to socio-demographic characteristics:

$\square$ Age 


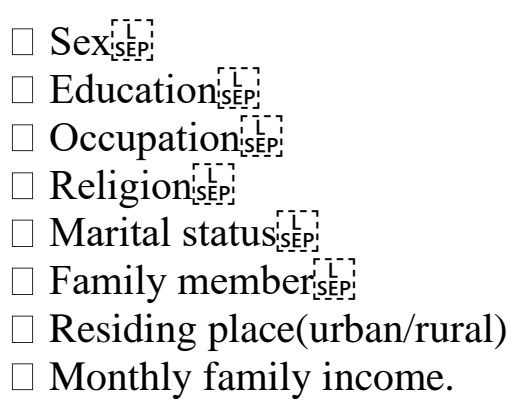

\section{Conceptual Framework}

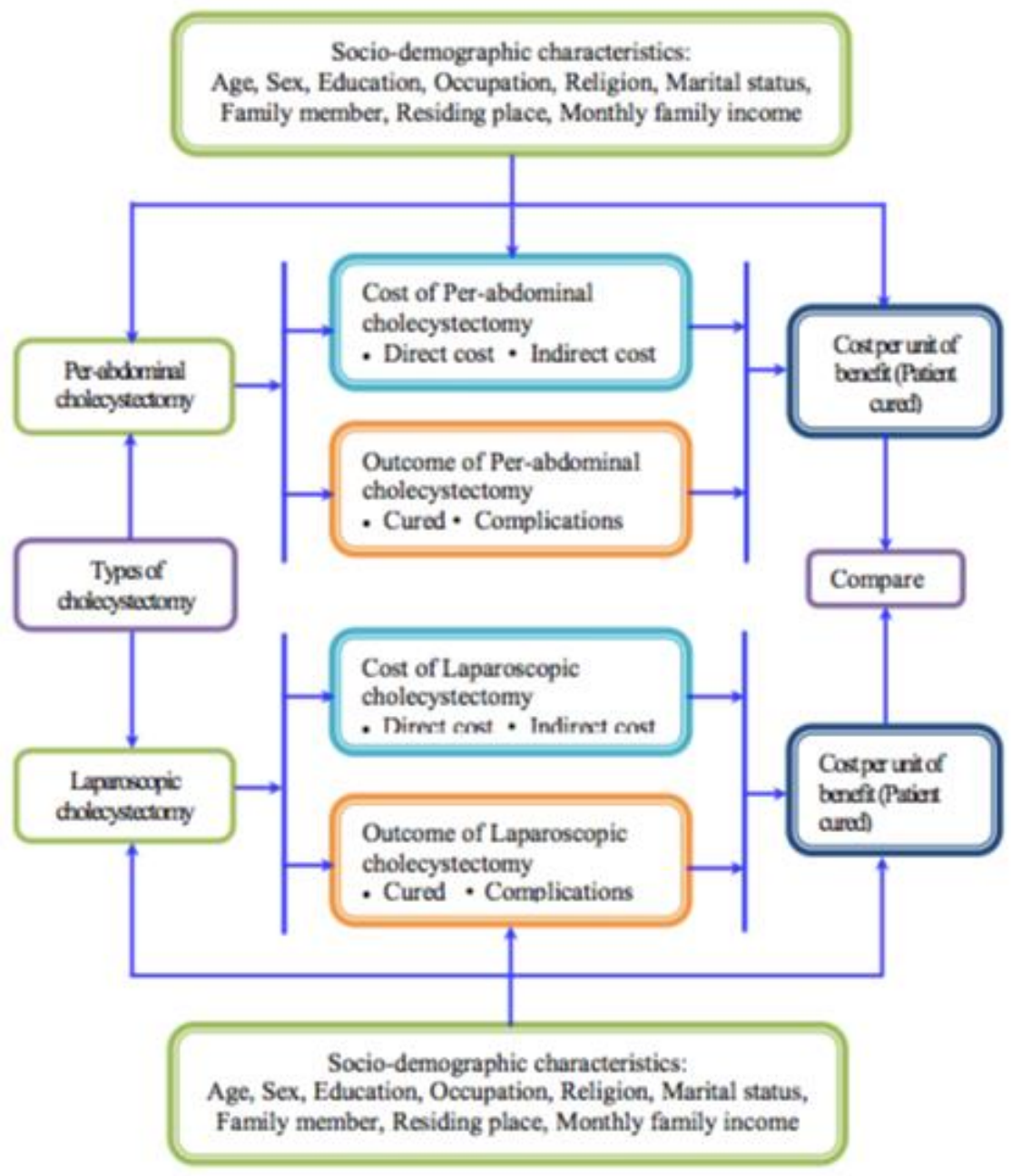




\section{Operational Definitions}

Per-abdominal Cholecystectomy:is regarded as a single incision of about 4 to 6 inches long in the upper right side of abdomen (Luschka, H.V., et al., 2008).

Laparoscopic Cholecystectomy: regarded as 3 to 4 very small incisions through which a long, thin tube called a laparoscope, a tiny video camera and surgical tools are put in (Luschka, H.V., et al., 2008).

Costs of Cholecystectomy: In this study costs are divided into the following -

Direct costs: Direct costs of this study include following -

$\square$ Consultation fee

$\square$ Hospital costisepin

Drug cost

Laboratory investigation cost

$\square$ Travel cost

Food cost

Attendant cost (Drummond,M.F.etal.,2005).

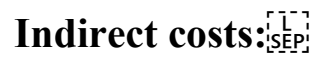

$\square$ Loss of income

$\square$ Family costis

$\square \square$ Tips for treatmentis

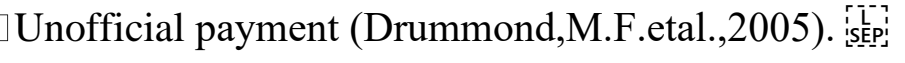


Outcome of Cholecystectomy: In this study outcomes are as follows -

$\square$ Cured: Patient's condition improves after surgical intervention. ične

$\square$ Complications: It may be - is

$\square$ Per-operative complication-Bile duct injury, Hemorrhage etc.

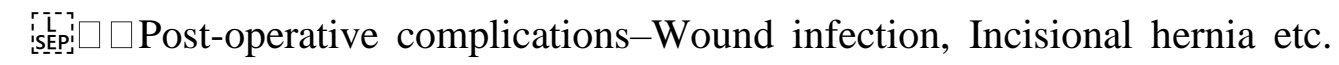
ín

$\square$ Duration of hospital stay (Ray-Offor, E. et al., 2014).

\section{Literature Review}

\section{Cholelithiasis (Gallstone Disease)}

The prevalence of gallstones varies with ethnic group and geographical location. The lowest prevalence, approximately $5 \%$, is found in Asia and Africa (Shaffer, E.A., 2006). In the developed countries, gallstones are common, with prevalence as high as $10-15 \%$ of the adult population (Aerts, R. et al., 2003). The highest prevalence is found among North American Indians, in whom they afflict $64 \%$ of women and $30 \%$ of men (Everhart, J.E. et al., 2002).

There are two main types of gallstones: cholesterol stones and pigment stones. Cholesterol stones form when there is super-saturation of bile with cholesterol (Johnston, D.E. et al., 1993). In the supersaturated bile, cholesterol and phospholipids start to form cholesterol-rich vesicles and make bile lithogenic. Crystal nucleation takes place in lithogenic bile when cholesterol-rich vesicles precipitate into crystals (Konikoff, F.M. et al., 2000). The crystallization is accelerated by several pronucleating factors, including mucin glycoproteins, immunoglobulins, and transferrin (Jirsa, M. et al., 2001). Formation of stones is further encouraged by decreased gallbladder motility. In the developed countries, roughly $80 \%$ of all gallstones are cholesterol stones (O’Connell, K. et al., 2014).

Pigment stones account for most of the remaining $20 \%$ of gallstones in developed countries. Pigment stones are of two types- brown pigment stones and black pigment stones. Black pigment stones consist of $70 \%$ calaparoscopic cholecystectomyium 
bilirubinate and are associated with haemolytic conditions and chronic liver disease. Brown pigment stones form as a result of stasis and infection within the biliary tract. Unlike cholesterol stones, brown pigment stones are identified mostly as primary ductal stones forming within the intrahepatic and extrahepatic bile ducts (O'Connell, K. et al., 2014).

Gallstone disease can be divided into asymptomatic, symptomatic and complications of gallstones. During follow-up, most gallstones remain asymptomatic. The majority will not develop symptoms: up to $80 \%$ will never experience biliary pain or complications like acute cholecystitis, cholangitis, and/or pancreatitis. The risk of progression to symptomatic disease is quite low averaging 2-4\% per year (Sakorafas, G.H. et al., 2007).

\section{Treatment of Cholelithiasis (Cholecystectomy)}

Treatment of cholelithiasis is done by surgical removal of gallstone i.e. cholecystectomy either routinely as early as possible or followed by conservative treatment. It may be performed by traditional per-abdominal method or laparoscopic method. A recent meta-analysis did not find any significant differences in overall mortality and morbidity, which ranged from $0 \%$ to $3 \%$ and $13 \%$ to $20 \%$, respectively, when results were compared in randomized trials on management of gallbladder stones by per-abdominal surgery, laparoscopic surgery, and various laparoscopicendoscopic protocols (Dasari, B.V.M. et al., 2013).

Additionally, laparoscopic one-stage management seems to be associated with a shorter hospital stay and lower total costs than two-stage laparoscopic-endoscopic protocols are. Yet cost-effective laparoscopic CBDE remains both time-consuming and technically demanding, and it requires dedicated instruments. In addition, consensus has not been reached on CBDS management, and endoscopic treatment remains largely preferred worldwide (Costi, R. et al., 2014).

\section{Per-abdominal Cholecystectomy}

For patients in whom a laparoscopic approach is not indicated or in whom conversion 
from a laparoscopic approach is required, per-abdominal cholecystectomy is performed. A short right upper transverse incision is made centred over the lateral border of the rectus muscle. The gall bladder is appropriately exposed and dissected away from the gall bladder bed (Luschka, H.V. et al., 2008).

Carl Langenbuch was performed the first cholecystectomy in Berlin in 1882 (Langenbuch, C. 1882). Nowadays, most per-abdominal cholecystectomy is performed through a right subcostal (Kocher) incision. Also, an upper midline incision is widely used. Classically, the retrograde technique, wherein the gallbladder is mobilized from its fundus towards the porta hepatis, is employed. The anterograde approach, from porta hepatis towards the fundus, has gained popularity in recent years among younger surgeons because of their laparoscopic experience (Visser, B.C. et al., 2008).

Nevertheless, the retrograde technique is particularly strongly indicated when severe inflammation is present. During per-abdominal cholecystectomy, the biliary tract can be assessed with palpation, intra-operative cholangiography (IOC), or intra-operative ultrasonography. In per-abdominal cholecystectomy, the IOC is typically performed via cystic duct or via needle puncture to the CBD. Nowadays, routine IOC is not recommended (Ford, J.A. et al., 2012).

Currently, per-abdominal cholecystectomy is used mainly when the procedure is converted to a per-abdominal one during laparoscopic cholecystectomy or because laparoscopic cholecystectomy is contraindicated or when cholecystectomy is performed in conjunction with another per-abdominal procedure. Additionally, perabdominal cholecystectomy is still performed particularly often for elderly patients (Saia, M. et al., 2013) and in cases of acute cholecystitis (Dolan, J.P. et al., 2009).

\section{Indications}

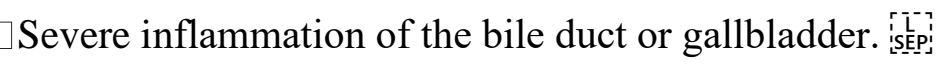

$\square$ Inflammation of the abdominal lining (peritonitis).

$\square$ High pressure in blood vessels in the liver (portal hypertension). This is

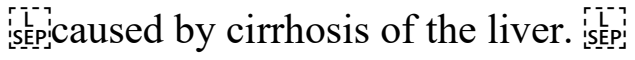

$\square$ Being in the third trimester of pregnancy. istepi 
$\square \square \square \square \square$ A major bleeding disorder or use of medicines to prevent blood clotting

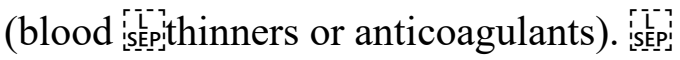

Scar tissue from many previous abdominal surgeries.

Abnormal anatomy in the abdomen (Glasgow, R.E. et al., 2010). 'i[

\section{Laparoscopic Cholecystectomy is}

Laparoscopic cholecystectomy is the procedure of choice for the majority of patients with gall bladder disease. The key, as in per-abdominal surgery, is identification and safe dissection of Calot's triangle. The gall bladder is removed from the gall bladder bed by sharp dissection and once free, removed via the umbilicus. An endobag may be used for extraction of the gall bladder to prevent contamination of the umbilical

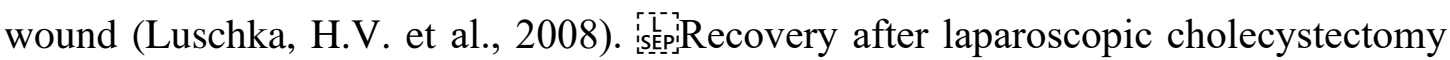
is rapid $-80 \%$ of patients are discharged within 24 hours and the remainder by day 2 . Any untoward symptoms require immediate investigation. Serious complications of laparoscopic cholecystectomy fall into two major areas: access complications or bile duct injuries. In the main, access complications occur during the insertion of the Verres needle to establish pneumoperitoneum or the insertion of trocars. If insertion is performed sisepiblindly or is found to be difficult, visceral injury should be excluded. If either a visceral or a bile duct injury is suspected, conversion to an per-abdominal technique is recommended by most surgeons (Luschka, H.V. et al., 2008).

In 1985, E. Muhe performed the first laparoscopic cholecystectomy, in Germany (Muhe, E., 1986). Laparoscopic cholecystectomy became popular in the early 1990s and is now considered the gold standard for the treatment of symptomatic gallstone disease in developed countries (Fletcher, D.R. et al., 1999). In the American laparoscopic cholecystectomy technique, the surgeon is positioned to the left of the patient, whereas the French approach places the patient in a split leg position with the surgeon standing between the patient's legs (Kramp, K.H. et al., 2014).

The standard technique employs four ports, the position of which depends on which of these two techniques is used. In the American technique, the camera port is usually placed in the periumbilical region, the operating port in the epigastrium, and both the liver retractor and the grasper in the upper right quadrant. In the French technique, the 
camera port is still in the periumbilical region, but the operating port is typically placed in the upper left quadrant, the liver retractor in the epigastrium, and the grasper in the upper right quadrant. The American and the French techniques are reported to be comparable in safety, if correctly used (Nuzzo, G. et al., 2005).

The anterograde (from porta hepatis towards the fundus) technique of dissection is typically used in laparoscopic cholecystectomy. New techniques to even minimize laparoscopic cholecystectomy have been proposed lately, including natural orifice transluminal surgery, or NOTES, both transgastric and transvaginal, and singleincision laparoscopic surgery. In addition, several fewer than four port laparoscopic cholecystectomy techniques have been introduced. However, the benefits of these techniques over traditional four-port laparoscopic cholecystectomy have yet to be proved (Gurusamy, K.S. et al., 2014).

\section{Indications}

The indications for surgery have remained the same for laparoscopic cholecystectomy as they were for per-abdominal cholecystectomy in the pre-laparoscopic era, with symptomatic and complicated gallstone disease being the most important indications (Overby, D.W. et al., 2010).

Indications for laparoscopic cholecystectomy in cases of asymptomatic gallbladder disease (Sakorafas, G.H. et al., 2007).

$\square$ Risk of malignancy:

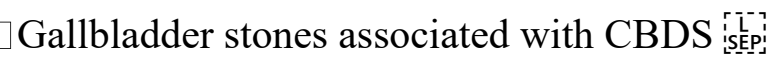

$\square$ Being a transplant patient (before or during transplantation) is isep

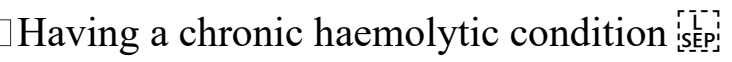

Increased risk of conversion from asymptomatic to symptomatic disease:

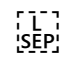

$\square$ Diabetes mellitus [ic

$\checkmark$ Symptoms of dyspepsia in the presence of gallstones

$\square$ Pregnant patients with symptomatic gallbladder stones, no matter the

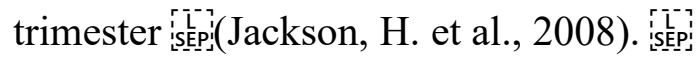




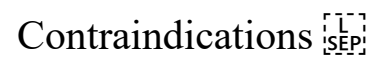

Comorbid conditions that the patient unable to tolerate general anaesthesia, such as serious cardiopulmonary diseases. [is.pi

$\square$ Relative contraindications include - generalized peritonitis, septic shock, severe acute pancreatitis, untreated coagulopathy, advanced cirrhosis with failure of hepatic function, suspected gallbladder cancer, and previous abdominal operations that preclude a minimally invasive approach (Overby, D.W. et al., 2010).

\section{Costs of Cholecystectomy}

While there is general agreement as to the clinical benefits of laparoscopic over perabdominal cholecystectomy, the costs of both procedures are still a subject of controversy. Only few studies have placed their emphasis on comparing costs

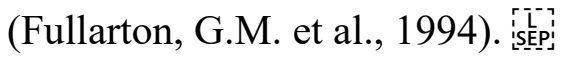

\section{Costs of Per-abdominal Cholecystectomy}

Costs of per-abdominal cholecystectomy include some direct cost like consultation fee, hospital cost, drug cost, laboratory cost, travel cost, foods cost, attendant cost and some indirect costs like loss of income, family cost, tips for treatment and unofficial payment (Drummond, M.F. et al, 2005). išmp

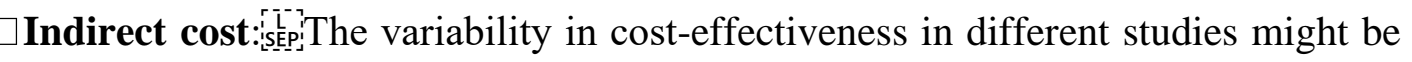
attributed to difference in structure of indirect costs. These indirect costs include factors such as, is sepperper day bed cost of hospital, cost of absenteeism from occupation, cost of attendant and caregivers and cost of post-operative medication. These costs vary substantially in different environments (Shukla, A. et al., 2017).

$\square$ Total cost: A literature showed that the average cost of per-abdominal cholecystectomy US\$ 1,048 was more than laparoscopic cholecystectomy and it was not cost-effective than laparoscopic cholecystectomy (Fajardo, R. et al., 2011). In another study, the cost of the laparoscopic procedure was higher than that for perabdominal surgery (El-Fellah, N. et al., 2011). The median total costs of the hospital 
was 150.87 euros, statistically higher in the per-abdominal group i.e. 231.62 US dollars ( $\mathrm{p}=0.0001)$ comparing laparoscopic cholecystectomy (Majbar, M.A. et al., 2015). In another study, average cost of treatment was rupees $12152(\mathrm{p}=0.007)$ significantly higher in the per-abdominal group compared to laparoscopic group (Shukla, A. et al., 2017).

Per-abdominal cholecystectomy costs and effectiveness values were \$2058.72 with 0.75 QALYs (Silverstein, A. et al., 2016). According to Stevens, H.P. et al. the cost involved in per-abdominal surgery is found to be more than in laparoscopic surgery (Stevens, H.P. et al., 1997). In one study there was not much cost different between both procedures (Carbajo, C.M. et al., 1998). According to the Doke, A. et al., (2016), per-abdominal surgery averagely worked out to cost about 9,000-10,000 rupees. (Doke, A. et al., 2016).

A study done in Bangladesh showed that total cost of per-abdominal surgery is more than laparoscopic surgery though operation team charge is less. Where per-abdominal operation cost was BDT.8110.00, medicine cost was BDT.15091.00 and total cost was BDT.30685.00. Authors argued that this was due to increase hospital stay and increase medication cost for per-abdominal surgery (Rahman, M.S. et al., 2016).

\section{Costs of Laparoscopic Cholecystectomy}

Costs of laparoscopic cholecystectomy can be divided into some direct costs like consultation fee, hospital cost, drug cost, laboratory cost, travel cost, foods cost, attendant cost and some indirect costs like loss of income, family cost, tips for treatment and unofficial payment (Drummond, M.F. et al, 2005).

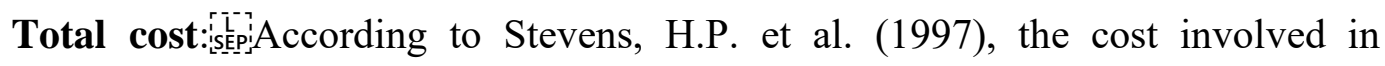
laparoscopic surgery is found to be less than in per-abdominal surgery (Stevens, H.P. et al., 1997). But in other study there was not much cost difference between both procedures (Carbajo, C.M. et al., 1998). Other literature showed that the average cost of laparoscopic cholecystectomy was lower than per-abdominal cholecystectomy and laparoscopic cholecystectomy was more cost-effective than per-abdominal cholecystectomy (US\$ 995 vs. US\$ 1,048, respectively) (Fajardo, R. et al., 2011). In another study, the cost of the laparoscopic procedure was 
higher than that for per-abdominal surgery (El- Fellah, N. et al., 2011). The financial cost per laparoscopic cholecystectomy was US\$ 495.00 and it was more than per-abdominal surgery (US\$ 435.00) (Medeiros, A.C. et al., 2012).

According to Majbar, M.A. et al., (2015), median total costs of the hospital for cholecystectomy was 150.87 Euros and it was statistically lower in the laparoscopic group i.e. 169 US dollars, $\mathrm{P}=0.0001$. The laparoscopic cholecystectomy costs and effectiveness values were $\$ 2664.47$ with 0.87 quality adjusted life years (QALYs) (Silverstein, A. et al., 2016). According to the Doke, A. et al. (2016) study laparoscopic surgery averagely worked out to cost about 11,500-12,500 rupees and it was more than per-abdominal surgery. (Doke, A. et al., 2016).

Rahman, M.S. et al., (2016) in their study found that total cost of laparoscopic cholecystectomy was less than per-abdominal surgery though operation team charge is more in laparoscopic surgery. In this study laparoscopic operation cost was BDT.9920.00 whereas medicine cost was BDT.8691.00 and total cost was BDT.22738.00 (Rahman, M.S. et al., 2016). Another study showed that average cost of laparoscopic treatment was rupees 10870, and the mean cost of treatment was significantly higher in the per-abdominal group compared to laparoscopic group (Shukla, A. et al., 2017).

\section{Outcome of Cholecystectomy}

Cholecystectomy has been performed for over 100 years and is a safe operation with a low rate of morbidity and minimal mortality. At the advent of the current laparoscopic era, several studies reviewing tens of thousands of patients confirmed that the perabdominal cholecystectomy was indeed the gold standard for the treatment of symptomatic gallstones. The overall mortality rate in these studies averaged less than $0.5 \%$, with one population-based study of 42,474 patients documenting a mortality rate of $0.17 \%$ (Patrick, J.J. et al., 2004).

\section{Outcome of per-abdominal cholecystectomy}

Although laparoscopic cholecystectomy has become the standard of care for symptomatic cholelithiasis and cholecystitis, $10 \%$ to $30 \%$ of cholecystectomies are 
still performed in per-abdominal fashion. Because the total number of cholecystectomies is increasing with time, the average patient undergoing perabdominal cholecystectomy in the laparoscopic era is older and has more comorbidities (Wolf, A.S. et al., 2009).

$\square$ Complication: The total rate of complications in the per-abdominal cholecystectomy group was $7.7 \%$, with five postoperative deaths. Multivariate analysis for per-abdominal cholecystectomy revealed that both old age $(p=0.014)$ and the existence of common bile duct stones $(\mathrm{p}=0.02)$ had independent prognostic influences in increasing the overall complication rate. Multivariate analysis of all cholecystectomies $(n=1440)$ showed that the overall complication rate was influenced independently by per-abdominal cholecystectomy as a detrimental factor (Jatzko, G.R. et al., 1995).

Major complications occurred in five patients (10.4\%) in per-abdominal cholecystectomy. In this study, post-operative morbidity rates were reported to be higher in per-abdominal surgery as compared to laparoscopic surgery (Hosseini, S.N. et al., 2008). Teixeira, J.A. et al. reported in per-abdominal cholecystectomy, mortality was $3.7 \%$ ( $\mathrm{p}=0.0369)$; per-operative complications was $12.9 \%$ ( $\mathrm{p}=0.0006)$; surgical postoperative complications was $17.5 \% \quad(\mathrm{p}=0.0055)$ and medical postoperative complications was $5.5 \%$ ( $\mathrm{p}=0.6077$ ) (Teixeira, J.A. et al., 2014).

The overall frequency of postoperative complications was relatively high in perabdominal group $50.5 \%$ as compared to laparoscopic group including all minor and major problems with combined morbidity of $43.75 \% \quad(\mathrm{P}<0.001)$. Frequency of postoperative complications assessed was also higher in per-abdominal group as compared to laparoscopic group (Talpur, K.A.H. et al., 2011). The study showed that frequency of complications was higher i.e. $13.5 \%$ for per-abdominal cholecystectomy than laparoscopic cholecystectomy (Fajardo, R. et al., 2011). Rahman, M.S. et al., 2016 reported in this series there is no significant difference in complications between laparoscopic and per-abdominal cholecystectomy (Rahman, M.S. et al., 2016).

$\square$ Wound infection:isepiThe chance of wound problems and cardiopulmonary complications with per- abdominal approach is much higher than laparoscopic cholecystectomy (Zacks, S.L. et al., 2002). 
The average rate of wound infections in per-abdominal cholecystectomy was 1.4$5.4 \%$ (Kaafarani, H.M. et al., 2010). In a study it was found that complications occurred in $11.5 \%$ patients. Among them wound infections occurred in $9.3 \%$ in the per-abdominal group. There were statistically more infectious complications in the per-abdominal group ( $\mathrm{p}=0.04$ ) (Majbar, M.A. et al., 2015). Proportion of patients with wound infection and abdominal distension was significantly higher in per-abdominal surgery as compared to laparoscopic surgery (Hosseini, S.N. et al., 2008). A study by Coccolini, F. et al. (2015) on over 1248 patients (677 of laparoscopic and 697 of perabdominal cholecystectomy) reported that the post-operative morbidity rate was double for per-abdominal cholecystectomy compared to laparoscopic cholecystectomy (Coccolini, F. et al., 2015). Doke, A. et al., (2016) in their study found that $16 \%$ had wound infection (Doke, A. et al., 2016). However wound sepsis $(13.5 \%)$ was particular problem of per-abdominl group group (Talpur, K.A.H. et al., 2011).

Bile duct injury: complications. The first one had biliary leakage from the drain that resolved spontaneously after few days (Majbar, M.A. et al., 2015). Lesion of the main bile duct was $1.8 \%(p=0.6091)$ in per- abdominal group (Teixeira, J.A. et al., 2014).

Bleeding: isep Doke, A. et al., (2016) in their study found that $28 \%$ of patients who underwent per- abdominal surgery had complications. In this study $12 \%$ of patients who underwent per-abdominal cholecystectomy had excessive bleeding, only $8 \%$ of whom had about 50-200 $\mathrm{ml}$ of bleeding and $4 \%$ in the per-abdominal cholecystectomy group had more than $200 \mathrm{ml}$ of blood loss Doke, A. et al., 2016). The postoperative bleeding observed from drain was minor and stopped within 24-48 hours (Talpur, K.A.H. et al., 2011).

Hospital stay: The mean hospital stay was significantly shorter $(\mathrm{p}<0.01)$ in the LC group (7.6 days) than in the OC group (15.0 days) (Jatzko, G.R. et al., 1995). Laparoscopic cholecystectomy is associated with a shorter hospital stay and quicker convalescence as compared to classical per-abdominal cholecystectomy. The hospital stay in this study ranged from 3-30 days in per-abdominal cholecystectomy with mean length of hospitalization was $5.56 \pm 2.98$ days which was significantly higher compared to laparoscopic group (P 0.001) (Keus, F. et al., 2006).

There was a statistically significant difference between acute laparoscopic and perabdominal cholecystectomy in terms of hospital stay where mean of hospital stay was 5.4 days in per-abdominal cholecystectomy (Hosseini, S.N. et al., 2008). The hospital stay was significantly longer for per-abdominal cholecystectomy patients ranging 
from 4-10 days (91\%) as compared to laparoscopic group. The mean hospital stay was $5.56 \pm 2.98$ days in per-abdominal cholecystectomy (Talpur, K.A.H. et al., 2011).

Patients who underwent per-abdominal cholecystectomy had longer in hospital stay than those who underwent laparoscopic cholecystectomy. According to Doke, A. et al. $96 \%$ of patients in the study had a hospital stay of less than 5 days but all patients who underwent per-abdominal surgery were hospitalized postoperatively for more than 5 days (Doke, A. et al., 2016). In this study the median duration of hospital stay was seven days for per-abdominal cholecystectomy group (Shukla, A. et al., 2017).

\section{Outcome of laparoscopic cholecystectomy}

When compared to per-abdominal cholecystectomy, laparoscopic cholecystectomy is associated with lower mortality and morbidity. Morbidity rates of 4.8-6.4\% have been reported for laparoscopic cholecystectomy (Kaafarani, H.M. et al., 2010) whereas the reported mortality varies between $0.06 \%$ and $0.5 \%$ (Sandblom, G. et al., 2015).

Cure:i[e. Laparoscopic cholecystectomy was performed in 3100 patients. In 3088 $(99.61 \%)$ it was successful (Rai, M.A. et al., 2014).

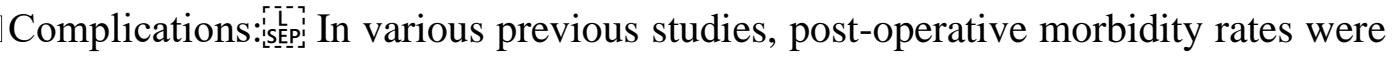
reported to be lower in laparoscopic surgery as compared to per-abdominal surgery. Major complications occurred in $5.1 \%$ patients in acute laparoscopic cholecystectomy compared to $10.4 \%$ in per-abdominal group (Hosseini, S.N. et al., 2008). Other study showed that frequency of complications was $6.4 \%$ for laparoscopic cholecystectomy (Fajardo, R. et al., 2011). performed in 3100 patients, complications were seen in $1.06 \%$ (Rai, M.A. et al., 2014). Majbar, M.A. et al., (2015) reported in their study that complications occurred in $11.5 \%$ patients. Wound infections occurred in one case $(1.8 \%)$ in the laparoscopic group. (Majbar, M.A. et al., 2015). In this series Rahman, M.S. et al., (2016) reported there is no significant difference in complications between laparoscopic and perabdominal cholecystectomy (Rahman, M.S. et al., 2016).

Wound infection: the main benefits of laparoscopic surgery (Cawich, S.O. et al., 2006) as the rate of 
surgical site infection is $2 \%$ versus $8 \%$ in per-abdominal surgery (Boni, L. et al., 2006). In another study it is reported as $1.4 \%$ in laparoscopic surgeries versus $14.8 \%$ in per-abdominl cases (Chuang, S.C. et al., 2004). Minor wound infection was seen in $30(0.96 \%)$ among laparoscopic cholecystectomy was performed in 3100 patients (Rai, M.A. et al., 2014).

Proportion of patients with wound infection and abdominal distension was significantly lower in laparoscopic surgery as compared to per-abdominal surgery. A study by Coccolini, F. et al., (2015) on over 677 of laparoscopic and 697 of perabdominal cholecystectomy reported that the post-operative morbidity rate was half for laparoscopic cholecystectomy compared to per-abdominal cholecystectomy. (Coccolini, F. et al., 2015). Port site infection developed in 5.2\% of laparoscopic cholecystectomy patients reported by Maitra, T.K. et al., (2017).

$\square \square$ Bile duct injury: complication of laparoscopic cholecystectomy and several studies report $0.5 \%$ to $1.4 \%$ incidence bile duct injuries (Rohatgi, A. et al., 2006). In another large case series, bile duct injury was minimum and occurred in only $3.98 \%$ cases. Vascular injury was encountered in another series. There were $9.97 \%$ cases of trocar site bleeding. Vascular injury in the Calot's triangle during dissection occurred in 57(16.23\%) cases (Chau, C.H. et al., 2006).

The most serious complication in laparoscopic cholecystectomy is bile duct injury, seen more frequently in laparoscopic cholecystectomy (1\% of cases) than perabdominal cholecystectomy ( $0.5 \%$ of cases) (Rai, M.A. et al., 2014). Intra-operative bile leak $(11.0 \%)$ was found to be the most frequent complications during laparoscopic cholecystectomy. The incidence rates of perforation of gall bladder, stone spillage were $9.3 \%$ and $5.2 \%$ respectively. Serious complications like bowel injury and bile duct injury were recorded in $0.6 \%$ and $1.2 \%$ cases respectively (Maitra, T.K. et al., 2017).

Bleeding: Only few data are available on the real incidence of bleeding complication from the liver bed. In a meta-analysis by Shea, 163 patients out of 15,596 suffered vascular injury required conversion with a rate of $8 \%$ (Shamiyeh, A. et al., 2004). Concomitant vascular injuries during laparoscopic cholecystectomy increase the overall morbidity (Tzovaras, G. et al., 2006). In a study it was found that trocar site, vascular, and hepatic bed hemorrhages were $7.0 \%, 4.7 \%$ and $4.0 \%$ 
respectively (Maitra, T.K. et al., 2017). Doke, A. et al., 2016 reported that $16 \%$ of patients who underwent laparoscopic surgery had developed complications. The overall percentage of complications was lesser in laparoscopic surgery than perabdominal surgery. $12 \%$ of patients according to author's study, who had undergone laparoscopic cholecystectomy, had minimal bleeding $(<50 \mathrm{ml})$ (Doke, A. et al., 2016).

$\square$ Hospital stay:i[ST The mean hospital stay was significantly shorter $(\mathrm{p}<0.01)$ in the laparoscopic group (7.6 days) than in the per-abdominal group (15.0 days), (Jatzko, G.R. et al., 1995). It is also comparable to other studies given by different authors like 5.1 days in per- abdominal versus 2.5 days in laparoscopic cholecystectomy (Syrakos, T. et al., 2004).

Laparoscopic cholecystectomy is associated with a shorter hospital stay and quicker convalescence as compared to classical per-abdominal cholecystectomy. The hospital stay in this study ranged 1-20 days in laparoscopic cholecystectomy with mean length of hospitalization was $3.02 \pm 1.75$ days which was significantly shorter than perabdominal group (P 0.001) (Keus, F. et al., 2006). The mean of hospital stay was 3.4 days in acute laparoscopic cholecystectomy groups. There was a statistically significant difference between acute laparoscopic and per-abdominal group in terms of hospital stay (Hosseini, S.N. et al., 2008).

The hospital stay was significantly shorter for laparoscopic cholecystectomy patients as compared to per-abdominal group where it was 1-5 days (94.5\%). The mean hospital stay was $3.02 \pm 1.75$ days in laparoscopic group. (Talpur, K.A.H. et al., 2011). Shorter hospital stay remains the main advantage of the laparoscopic cholecystectomy procedure. A study conducted by Anmol, N. et al., (2014) showed the same results.

The median duration of hospital stay was three days (interquartile range: 2 - 4.25). Patients in the laparoscopic group had a statistically shorter hospital stay (2.9 vs. 4.1 days, P < 0.0001). (Majbar, M.A. et al., 2015). 14 In this study the median duration of hospital stay was three days for laparoscopic cholecystectomy group and seven days for per-abdominal cholecystectomy group (Shukla, A. et al., 2017).

\section{Cost-effectiveness between per-abdominal and laparoscopic Cholecystectomy}


Solanki, K. et al., (2010) and Fajardo, R. R et al., (2011) in their study found laparoscopic cholecystectomy to be more cost effective. The variability in costeffectiveness in different studies might be attributed to difference in structure of indirect costs. These costs vary substantially in different environments and different perspective (Shukla, A. et al., 2017).

Silverstein, A. et al., (2016) compared the costs and effectiveness of laparoscopic and per-abdominal cholecystectomy. The incremental cost-effectiveness ratio for laparoscopic over per-abdominal cholecystectomy was found $\$ 4946.18$. The laparoscopic intervention was more cost-effective with investment costs less than $\$ 91,979$, greater than 65 cases annually, or at willingness-to-pay (WTP) thresholds greater than \$3975/QALY (Silverstein, A. et al., 2016).

\section{Materials and Methods:}

With the objective to assess the cost-effectiveness of per-abdominal and laparoscopic cholecystectomy, data were collected by interviewing the respondents and reviewing their medical records. Here is brief description of materials and methods followed in the study.

Study Design: This study was cross sectional in two sample situation which was done to assess cost-effectiveness of per-abdominal and laparoscopic cholecystectomy.

Study Period: This study was conducted during the period of January to December 2017. During the first quarter by reviewing literature, journal articles, and abstracts through internet I was interested in this thesis topic and with proper guidance I have selected thesis title and developed hypothesis, objectives and a conceptual framework with key variables. In this time period thesis protocol was submitted to Institutional Review Board of NIPSOM for ethical clearance. During the second quarter further literature review was done to develop informed written consent form and data collection instruments i.e. semi-structured questionnaire and checklist. After receiving clearance for data collection, during third quarter pre-testing was done and then finalization of the questionnaire and checklist was done. Data were collected during one month period. Then with the direct supervision of the supervisor data were analyzed and interpretation was done. Finally report writing was done for final submission.

Study Places: This study was conducted at the In-patient surgery department of 
following tertiary government hospital of Bangladesh -

$\square$ Dhaka Medical College \& Hospitalispep

$\square$ Sir Salimullah Medical College \& Hospitalisp̣p]

$\square \square$ Shaheed Suhrawardy Medical College \& Hospital.

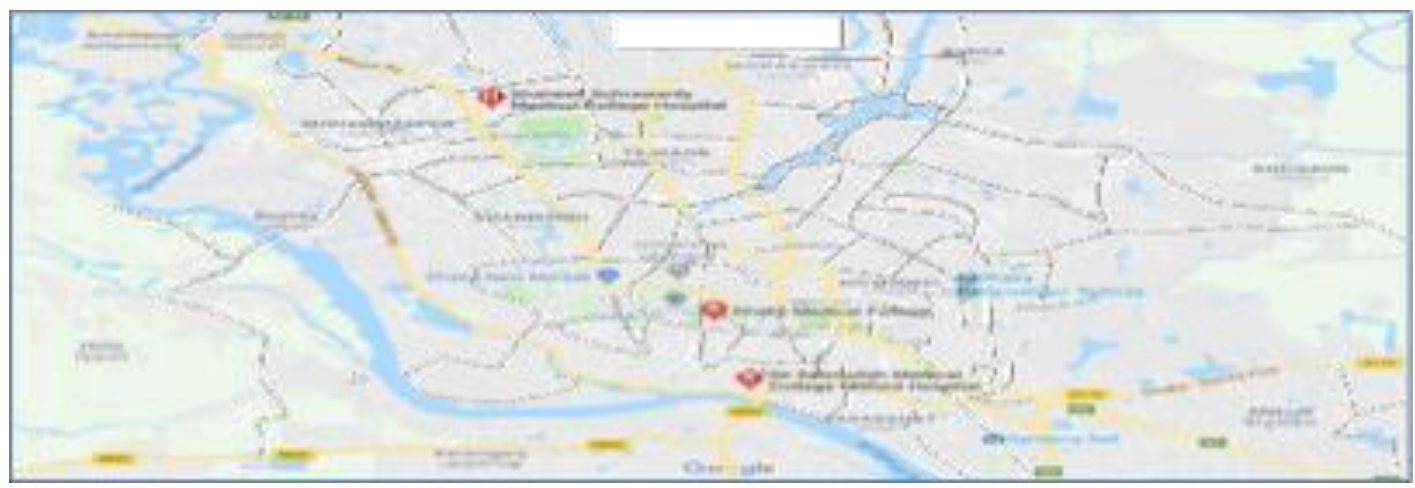

Map of study areas

Study Population: Following patient was included in the study -

$\square \square$ Cholelithiasis undergone per-abdominal Cholecystectomy:SEE:

$\square$ Cholelithiasis undergone laparoscopic Cholecystectomy.

Selection Criteria: Participants for this study were selected according to following criteria

Inclusion Criteria: Participants who had following criteria were included into this study -

$\square$ Diagnosed adult cholelithiasis patient underwent laparoscopic and perabdominal cholecystectomy. is⿱⺊口灬p?

$\square$ Both male and female patients. issp:

$\neg \square$ Patients who were provided informed written consent.

Exclusion Criteria: Participants who were not included in this study -

Seriously ill patients. is[ep?

Psychologically abnormal patients. [is:pep: 
Sample Size: The sample size was calculated considering following data:s[epispe:

- The overall complication rate of per-abdominal and laparoscopic cholecystectomy from the previous study conducted was $36 \%$ and $15.7 \%$ respectively. (Teixeira, J.A. et al., 2014)

The following formula was used for sample size calculation of this study.

$$
n=\left(\frac{\mathrm{r}+1}{\mathrm{r}}\right) \frac{\mathrm{P}(1-\mathrm{P})\left(\mathrm{Z}_{\beta}+\mathrm{Z}_{\alpha / 2}\right)^{2}}{\left(\mathrm{p}_{1}-\mathrm{p}_{2}\right)^{2}}
$$

Where,

$n=$ sample size in each group.

$\mathrm{r}=$ Ratio of two group $=1$

$Z_{\beta}=$ Represents $80 \%$ desired power $=0.84$

$\mathrm{Z}_{\alpha / 2}=$ Represents $5 \%$ significance level $=1.96$

Treatment outcome as complication -

$$
p_{1}=\text { complication rate of per-abdominal cholecystectomy }=36 \%=0.36
$$$$
p_{2}=\text { complication rate of laparoscopic cholecystectomy }=15.7 \%=0.157
$$$$
\mathrm{P}=\text { average proportion of two group }=\frac{p_{1}+p_{2}}{2}=(0.360+0.157) / 2=0.2585
$$

So, $\quad n=72.93$ (By rounding it was 75 )

The calculated sample size was $75 \square 2=150$. Among which 75 patients with perabdominal cholecystectomy and 75 patients with laparoscopic cholecystectomy.

Due to resource constrains and availability of sample, the sample size was 90. I could take 60 patients underwent laparoscopic cholecystectomy and 30 patients underwent 
per-abdominal cholecystectomy.

Sampling Technique: Purposive sampling technique was used to include the patients.

Data Collection Instruments: A semi-structured questionnaire was used to collect socio-demographic characteristics of the patients, information related to disease and treatment and costs of cholecystectomy incurred by the patients. A checklist was used to determine type and outcome of cholecystectomy.

Pre-testing: Prior to data collection, the questionnaire and checklist was pre- tested in Bangladesh Medical College \& Hospital. After pre-testing necessary modification and finalization of the questionnaire and checklist was done and then data collection started.

Data Collection Technique: Data were collected by face to face interview and reviewing medical records of the patients. Data were collected during the time of their discharge. After taking informed written consent, each patient was interviewed for about 30-40 minutes. Every day it was possible to collect data from 2-8 patients.

Data Processing: Data processing was done by following -

Data Cleaning: Data were cleaned by omission of any incomplete, inconsistent or irrelevant data. ¿ícpi]

Data Editing: Individual questionnaire and checklist was edited manually through checking and verifying whether it was filled completely.

Categorizing and post-coding of data: Data were coded and recoded according to variables and objectives of the study. [i[

Quality Control: At every step of data entry quality was maintained. 
Data Analysis: Data were analyzed by IBM statistical software. Both descriptive and inferential statistics were determined according to following statistical analysis plan -

\begin{tabular}{|l|l|}
\hline Variable & Statistical tests include \\
\hline $\begin{array}{l}\text { Qualitative variables: Sex, occupation, education, } \\
\text { religion, marital status, residing place etc. }\end{array}$ & $\begin{array}{l}\text { Frequency distribution by } \\
\text { tables and graphs }\end{array}$ \\
\hline $\begin{array}{l}\text { Quantitative variables: Age, monthly income, family } \\
\text { member, etc. }\end{array}$ & $\begin{array}{l}\text { Mean, Standard deviation } \\
\text { \& frequency distribution } \\
\text { by tables and graphs }\end{array}$ \\
\hline $\begin{array}{l}\text { Comparison between two means like treatment cost by } \\
\text { type of cholecystectomy. }\end{array}$ & t-test \\
\hline $\begin{array}{l}\text { Comparison between more than two means like treatment } \\
\text { cost by selective socio-demographic attributes. }\end{array}$ & ANOVA \\
\hline $\begin{array}{l}\text { Comparison association between two qualitative/ } \\
\text { categorical variables like sex, education, occupation, } \\
\text { religion, income group etc. }\end{array}$ & Chi-Square $\left(\chi^{2}\right)$ test \\
\hline $\begin{array}{l}\text { Correlation among treatment cost, age, income, duration } \\
\text { of disease, hospital stay etc. }\end{array}$ & Correlation, Regression \\
\hline
\end{tabular}

\section{Ethical Consideration:}

In this study the following ethical issues were considered

$\square$ Protocol Approval: At first with proper guidance of the supervisor protocol was developed. The protocol was presented to the board of protocol approval committee of NIPSOM. After scientific critical appraisal it was approved by the approval committee.

Ethical Clearance: According to prescribed format protocol was submitted to the Institutional Review Board (IRB) of NIPSOM for ethical clearance. After necessary actions IRB has given the ethical clearance and permission for data collection.

Administrative Permission: Ethical clearance provided by IRB of NIPSOM was 
shown to the authorities of respective hospital and permission was obtained. Then data collection was started.

Consent: To avoid potential risk or to keep the privacy of the patients an informed written consent was signed by them before interview. In Informed written consent detailed explanations about purpose, expectation, procedure of data collection, risk and benefit of the study was provided to the patients.

Confidentiality and anonymity: Confidentiality of the information provided by the patients was maintained strictly. No information even name of the patients was shared with others. All the information was used for this study purpose.

Respect: Each patient was given due respect during data collection. i[

Risk: Patients were assured that there was no physical, social, economical, psychological or legal risk to them. But there might have some discomfort to the

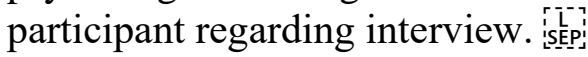

Benefit: No compensation or other benefits was provided to the patients.

\section{Limitations of the study}

$\square$ The study encountered limitations to ensure participation of the patients in the study especially to motivate them to recall the information of cost of treatment. ī'

Due to resource constraints, the study included limited patients underwent perabdominal cholecystectomy. So, equal number of sample could not be taken as laparoscopic cholecystectomy. Thus the study findings may not represent the real picture of the country. is

$\square$ Recall bias was faced to some extent by the study in respect of estimation of treatment costs especially in calculation of direct and indirect treatment costs.

$\square$ Time limitation was another consideration as this study was done with a tight SLẸpischedule it was not possible to collect all the sample as calculated.

$\square$ This study was conducted without financial support from any agency. So it iscepiwas done with limited number of sample which might not figure out the real scenario of the country. [istep? 


\section{Results}

The cross sectional study in two sample situations, was conducted to assess the costeffectiveness of per-abdominal and laparoscopic cholecystectomy. It was carried out among 90 patients (30 patients underwent per-abdominal cholecystectomy and 60 patients underwent laparoscopic cholecystectomy). They all were interviewed on some selected variables. Data were organized into different groups of variables. Appropriate descriptive and analytical statistics were done. All the findings are organized as follows.

\section{Distribution of the patients by types of cholecystectomy}

Regarding types of cholecystectomy, 30 (33.3\%) patients were taken with perabdominal cholecystectomy and $60(66.7 \%)$ patients were taken with laparoscopic cholecystectomy, which is shown in figure-1. 


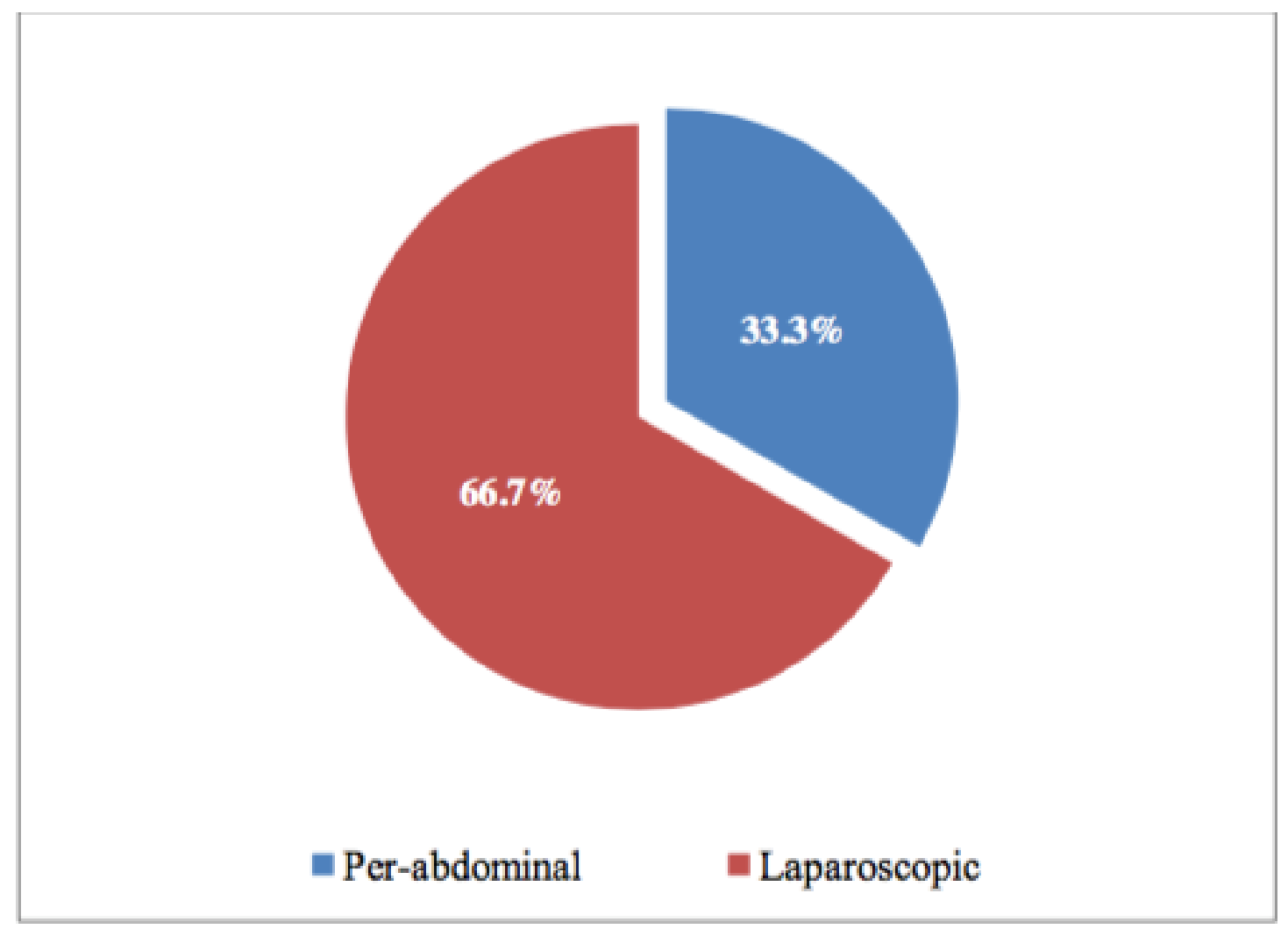

Figure-1: Distribution of the patients by types of cholecystectomy

\section{Sex distribution of the patients by cholecystectomy}

In respect of sex, among per-abdominal group, $76.7 \%$ patients were females and $23.3 \%$ were males. While among laparoscopic group, $76.7 \%$ patients were females and $23.3 \%$ were males, which are shown in figure- 2 . 


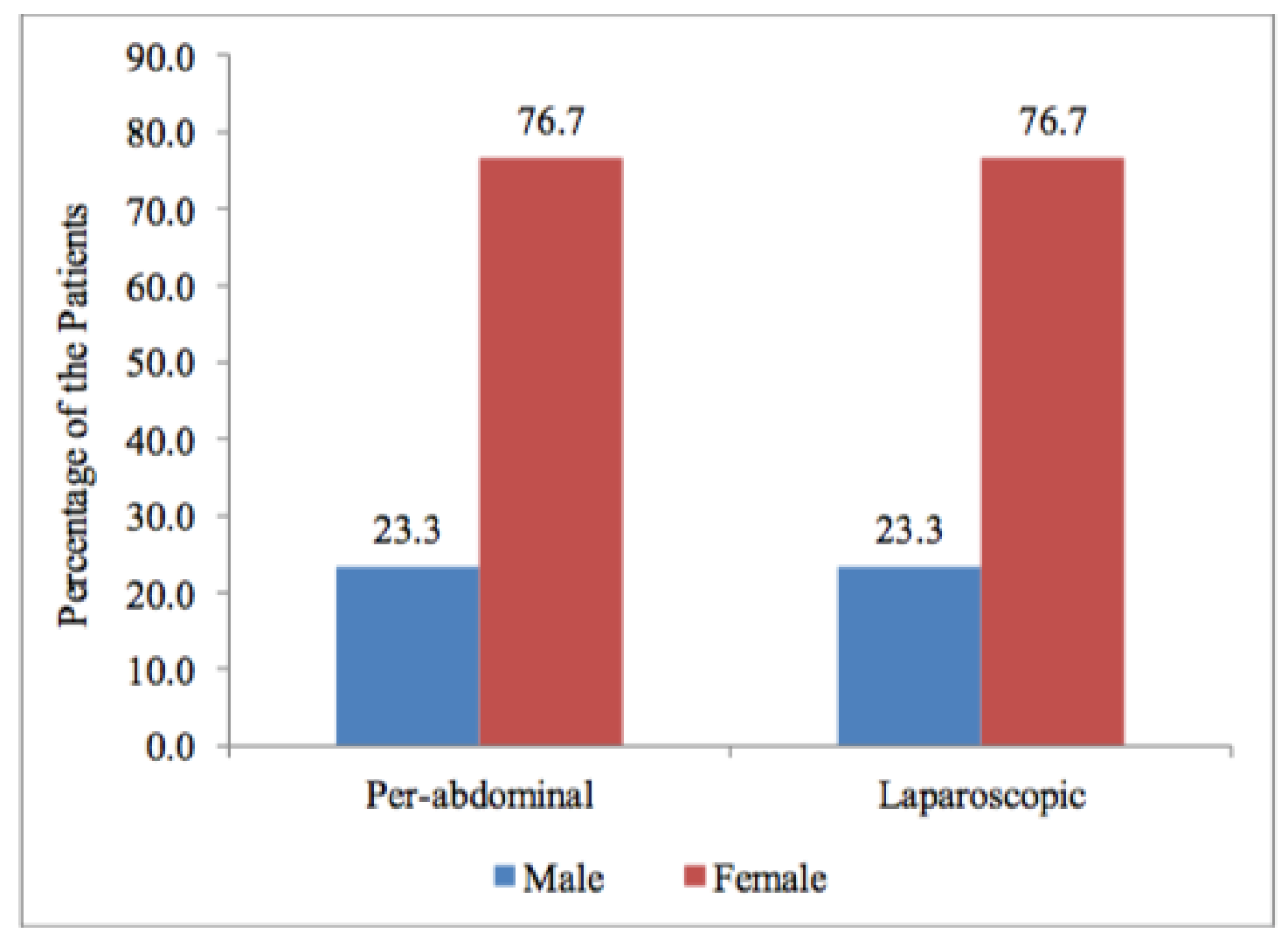

Figure-2: Distribution of the patients by sex and cholecystectomy

\section{Age distribution of the patients by cholecystectomy}

Regarding age, among per-abdominal group, majority i.e. $40 \%$ patients were in the age group 20-39 years and the average age of the patients of this group was $45.33( \pm 13.63)$ years. On the other hand, among laparoscopic group, majority i.e. $46.7 \%$ patients were in age group 40-59 years and the average age of the patients of this group was $41.75( \pm 13.39)$ years, which are documented in table-1.

Table-1: Distribution of the patients by age and cholecystectomy 


\begin{tabular}{|l|c|c|c|}
\hline \multirow{2}{*}{ Age (Yrs) } & \multicolumn{2}{|c|}{ Type of Cholecystectomy } & \multirow{2}{*}{$\begin{array}{c}\text { Total } \\
\mathrm{f}(\%)\end{array}$} \\
\cline { 2 - 3 } & $\begin{array}{c}\text { Per-abdominal } \\
\mathrm{f}(\%)\end{array}$ & $\begin{array}{c}\text { Laparoscopic } \\
\mathrm{f}(\%)\end{array}$ & $36(40.0)$ \\
\hline $20-39$ & $12(40.0)$ & $24(40.0)$ & $39(43.3)$ \\
\hline $40-59$ & $11(36.7)$ & $28(46.7)$ & $15(16.7)$ \\
\hline $60-69$ & $7(23.3)$ & $8(13.3)$ & $90(100.0)$ \\
\hline Total & $30(100.0)$ & $60(100.0)$ & $42.94( \pm 13.50)$ \\
\hline Mean( $( \pm \mathrm{SD})$ & $45.33( \pm 13.63)$ & $41.75( \pm 13.39)$ & \\
\hline
\end{tabular}

Marital status of the patients by cholecystectomy

Regarding marital status, among per-abdominal group, 70.0\% patients were married, followed by $26.7 \%$ were widow/widower while among laparoscopic group, $85.0 \%$ patients were married followed by $8.3 \%$ were widow/widower, which are reflected in figure-3.

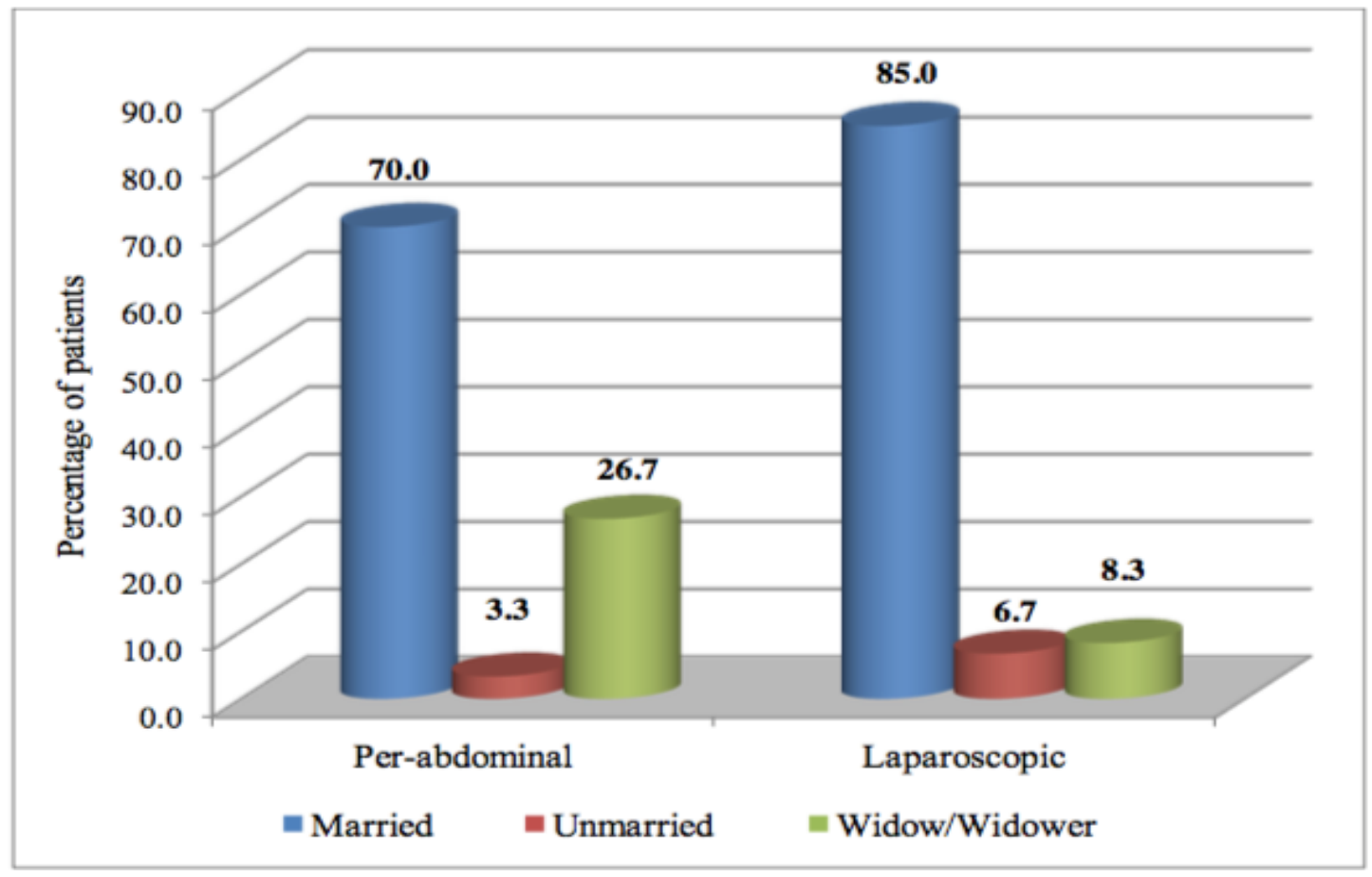

Figure-3: Distribution of the patients by marital status and cholecystectomy Residing place distribution of the patients by cholecystectomy 
By residing place, among per-abdominal group, 53.3\% patients were from urban areas and $46.7 \%$ were from rural areas. On the other hand, among laparoscopic group, $51.7 \%$ patients were from urban areas and $48.3 \%$ were from rural areas, which are depicted in figure-4.

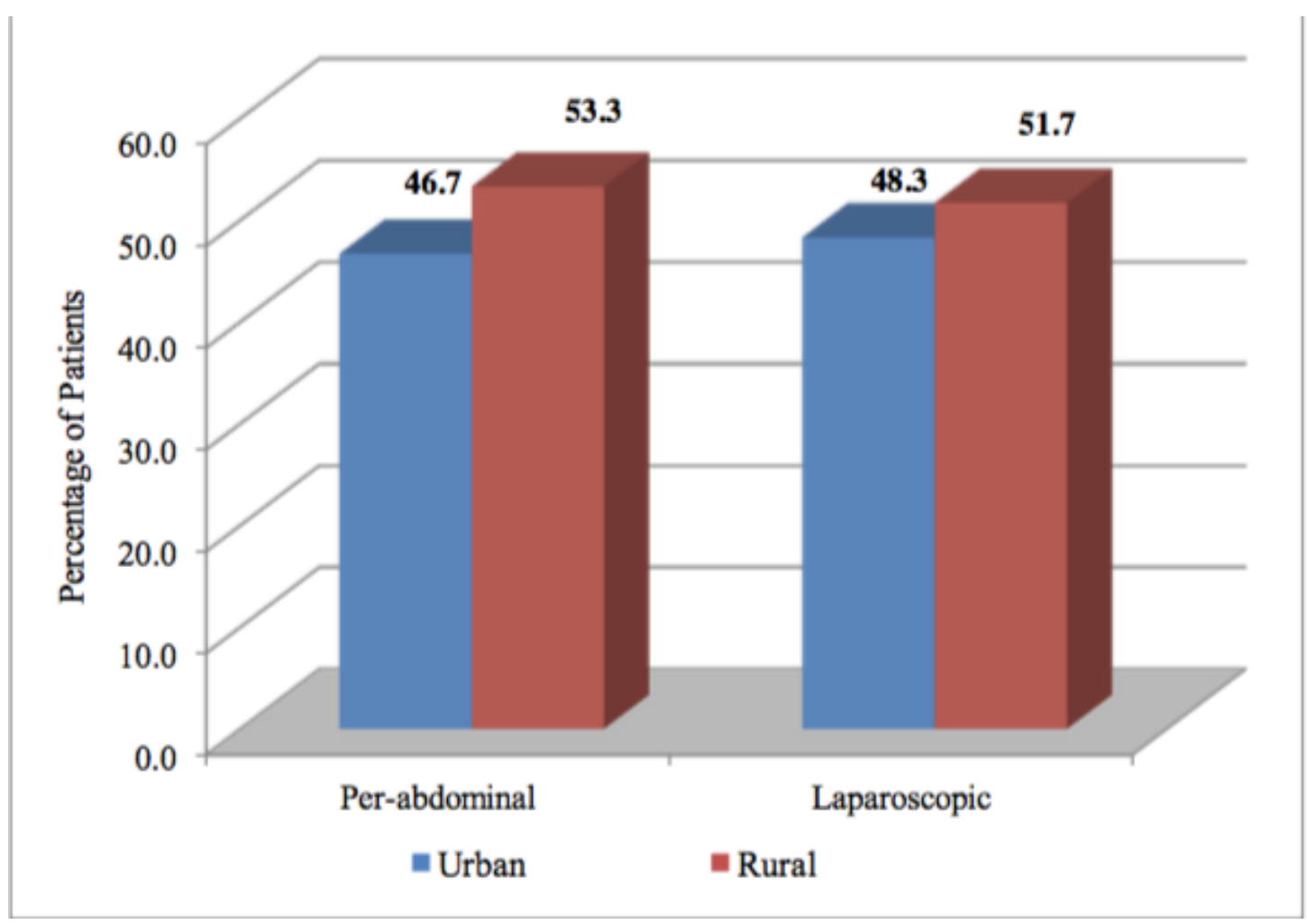

Figure-4: Distribution of the patients by residing place and cholecystectomy

\section{Duration of gallstone disease of the patients by cholecystectomy}

Regarding duration of gallstone disease, among per-abdominal group, 53.3\% patients were in 1-6 months group and 23.3\% were in 13-24 months group. On the other hand, among laparoscopic group, $70.0 \%$ patients were in 1-6 months group and $20.0 \%$ were in 25-48 months group. Average duration of gallstone disease was 9.50( \pm 8.68$)$ months in per-abdominal group while it was $12.43( \pm 17.49)$ months in laparoscopic group, which is reflected in table- 2 .

Table-2: Distribution of the patients by duration of gallstone disease and 


\section{cholecystectomy}

\begin{tabular}{|c|c|c|c|}
\hline \multirow{2}{*}{$\begin{array}{l}\text { Duration of gallstone } \\
\text { disease (Months) }\end{array}$} & \multicolumn{2}{|c|}{ Type of Cholecystectomy } & \multirow{2}{*}{$\begin{array}{l}\text { Total } \\
\mathrm{f}(\%)\end{array}$} \\
\hline & $\begin{array}{c}\text { Per-abdominal } \\
\mathrm{f}(\%)\end{array}$ & $\begin{array}{c}\text { Laparoscopic } \\
\mathrm{f}(\%)\end{array}$ & \\
\hline $1-6$ & $16(53.3)$ & $42(70.0)$ & $58(64.4)$ \\
\hline $7-12$ & $6(20.0)$ & $4(6.7)$ & $10(11.1)$ \\
\hline $13-24$ & $7(23.3)$ & $2(3.3)$ & $9(10.0)$ \\
\hline $25-48$ & $1(3.3)$ & $12(20.0)$ & $13(14.4)$ \\
\hline Total & $30(100.0)$ & $60(100.0)$ & $90(100.0)$ \\
\hline Mean $( \pm \mathrm{SD})$ & $9.50( \pm 8.68)$ & $12.43( \pm 17.49)$ & $11.46( \pm 15.14)$ \\
\hline
\end{tabular}

\section{First place of diagnosis of the patients by cholecystectomy}

In respect of first place of diagnosis of cholelithiasis, among per-abdominal group, $56.7 \%$ patients used government hospital followed by $30.0 \%$ patients used private hospital. On the other hand, among laparoscopic group, 31.7\% patients used government hospital followed by $58.3 \%$ patients used private hospital, which are shown in figure-5.

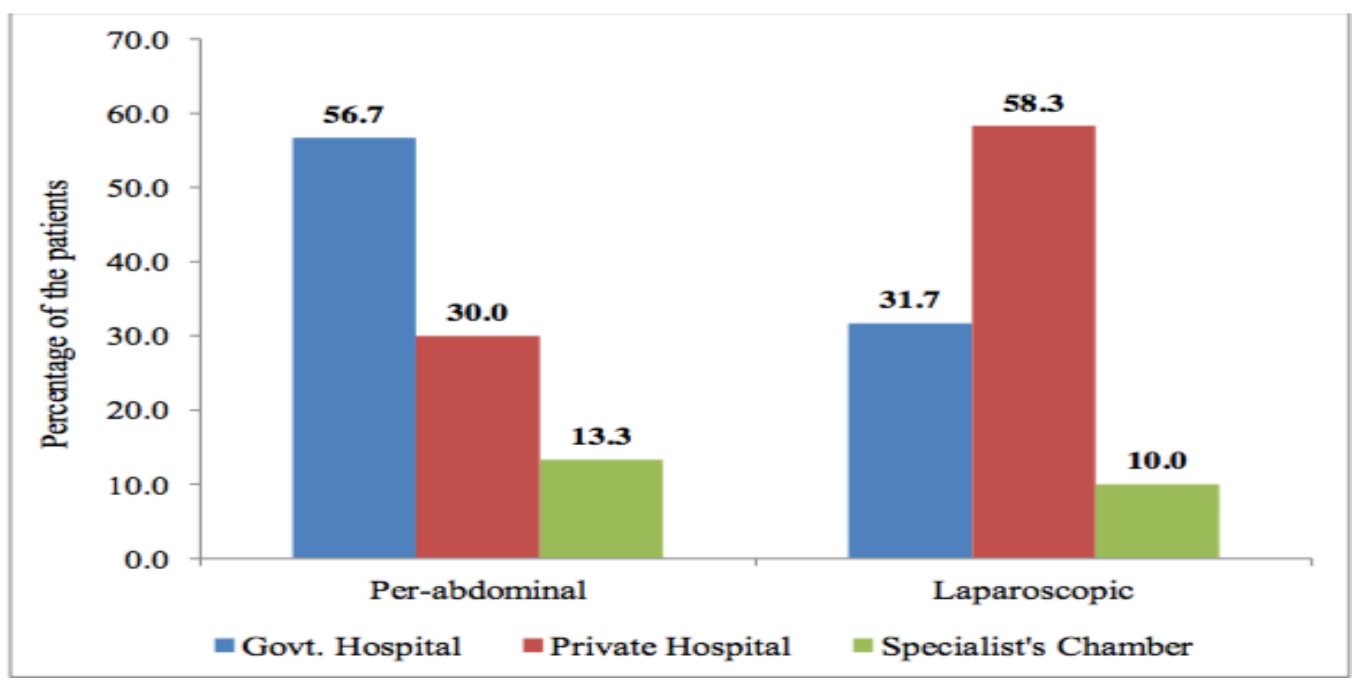

Figure-5: Distribution of the patients by first place of diagnosis and cholecystectomy

First place of treatment of the patients by cholecystectomy 
By first place of treatment, among per-abdominal group, 63.3\% patients used government hospital and $23.3 \%$ patients used private hospital whereas among laparoscopic group, $43.3 \%$ patients used government hospital and $46.7 \%$ patients used private hospital, which is depicted in figure-6.

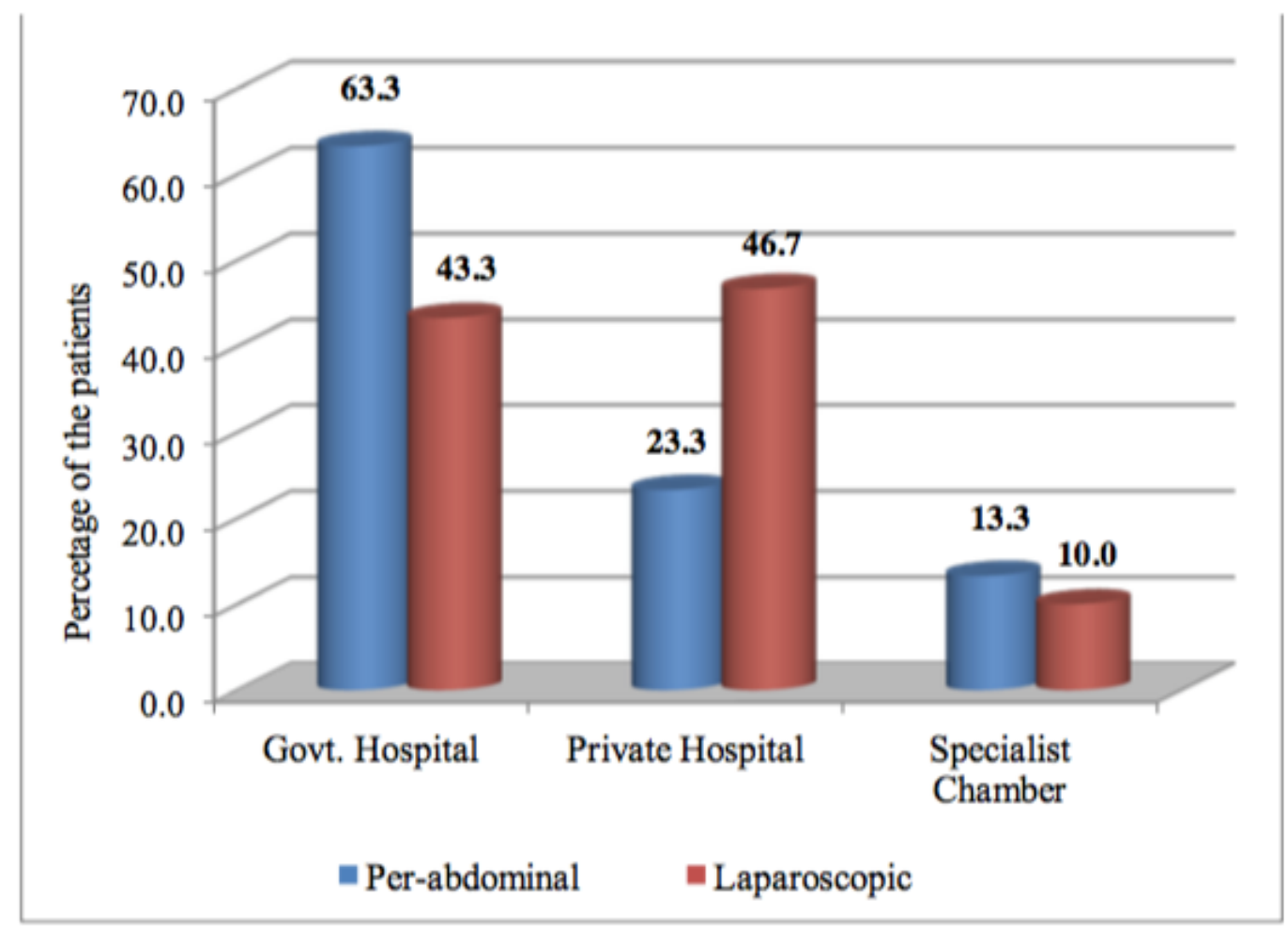

Figure-6: Distribution of the patients by first place of treatment and cholecystectomy

\section{Duration of hospital stay of the patients by cholecystectomy}

Regarding hospital stay, among per-abdominal group, 50.0\% patients were in 8-14 days group and $33.3 \%$ were in 15-30 days group while among laparoscopic group, $36.7 \%$ patients were in 8-14 days group and 33.3\% were in 3-7 days group. Average duration of hospital stay was $13.97( \pm 6.88)$ days in per-abdominal group while it was $12.02( \pm 6.66)$ days in laparoscopic group, which are shown in table-3.

Table-3: Distribution of the patients by duration of hospital stay and cholecystectomy 


\begin{tabular}{|l|c|c|c|}
\hline \multirow{2}{*}{$\begin{array}{c}\text { Duration of hospital } \\
\text { stay (Days) }\end{array}$} & \multicolumn{2}{|c|}{ Type of Cholecystectomy } & \multirow{2}{*}{$\begin{array}{c}\text { Total } \\
\mathrm{f}(\%)\end{array}$} \\
\cline { 2 - 3 } & $\begin{array}{c}\text { Per-abdominal } \\
\mathrm{f}(\%)\end{array}$ & $\begin{array}{c}\text { Laparoscopic } \\
\mathrm{f}(\%)\end{array}$ & $25(27.8)$ \\
\hline $3-7$ & $5(16.7)$ & $20(33.3)$ & $37(41.1)$ \\
\hline $8-14$ & $15(50.0)$ & $22(36.7)$ & $28(31.1)$ \\
\hline $15-30$ & $10(33.3)$ & $18(30.0)$ & $90(100.0)$ \\
\hline Total & $30(100.0)$ & $60(100.0)$ & $12.67( \pm 6.76)$ \\
\hline Mean( $( \pm \mathrm{SD})$ & $13.97( \pm 6.88)$ & $12.02( \pm 6.66)$ & \\
\hline
\end{tabular}

Different types of direct costs incurred by the patients (During last month) and cholecystectomy

Average consultation fee was Tk.772.73( \pm 343.78$)$ and Tk.832.26( \pm 388.49$)$ in perabdominal and laparoscopic group respectively. Majority i.e. 54.5\% patients of perabdominal group incurred Tk.100-500 and majority i.e. $58.1 \%$ patients of laparoscopic group incurred Tk.600-1000 consultation fee.

Average laboratory cost was Tk.4823.33( \pm 2096.42$)$ and Tk.5367.83( \pm 2361.06$)$ in per-abdominal and laparoscopic group respectively. Majority i.e. 83.3\% patients of per-abdominal group and $56.7 \%$ patients of laparoscopic group incurred Tk.10005000 laboratory cost.

Average drug cost was Tk.3086.67( \pm 641.51$)$ and Tk.3857.50( \pm 1615.57$)$ in perabdominal and laparoscopic group respectively. Majority i.e. $60.0 \%$ patients of perabdominal group and $35.0 \%$ patients of laparoscopic group incurred Tk.2100-3000 drug cost.

Average hospital cost was Tk.3851.67( \pm 2190.43$)$ and Tk.3296.77( \pm 2215.14$)$ in perabdominal and laparoscopic group respectively. Majority i.e. $46.7 \%$ patients of perabdominal group and $61.3 \%$ patients of laparoscopic group incurred Tk.1000-3000 
hospital cost.

Average travel cost was Tk.1490.00 $( \pm 542.89)$ and Tk.1405.00 $( \pm 625.84)$ in perabdominal and laparoscopic group respectively. Majority i.e. 53.3\% patients of perabdominal group and $46.7 \%$ patients of laparoscopic group incurred Tk.1100-2000 travel cost.

Average food cost incurred by the patients was Tk.1734.46( \pm 1341.91$)$ and Tk.1232.63( \pm 709.07$)$ in per-abdominal and laparoscopic group respectively. e Majority i.e. $42.9 \%$ patients of per-abdominal group incurred Tk.1100-2000 and majority i.e. 59.3\% patients of laparoscopic group incurred Tk.500-1000 food cost.

Average attendant's cost was Tk.5000.00( \pm 1860.11$)$ and Tk.4714.17( \pm 2319.70$)$ in per-abdominal and laparoscopic group respectively. Majority i.e. $70.0 \%$ patients of per-abdominal group and $63.3 \%$ patients of laparoscopic group incurred Tk.10005000 attendant's cost, which are depicted in table-4 \& 5.

Table-4: Distribution of the patients by different types of direct costs and cholecystectomy 


\begin{tabular}{|c|c|c|c|}
\hline \multirow{2}{*}{ Types of direct cost } & \multicolumn{2}{|c|}{ Types of cholecystectomy } & \multirow{2}{*}{$\begin{array}{l}\text { Total } \\
f(\%)\end{array}$} \\
\hline & $\begin{array}{c}\text { Per-abdominal } \\
f(\%)\end{array}$ & $\begin{array}{c}\text { Laparoscopic } \\
f(\%)\end{array}$ & \\
\hline \multicolumn{4}{|l|}{ Consultation fee } \\
\hline $100-500$ & $6(54.5)$ & $9(29.0)$ & $15(35.7)$ \\
\hline $600-1000$ & $4(36.4)$ & $18(58.1)$ & $22(52.4)$ \\
\hline $1100-2000$ & $1(9.1)$ & $4(12.9)$ & $5(11.9)$ \\
\hline Total & $11(100.0)$ & $31(100.0)$ & $42(100.0)$ \\
\hline $\operatorname{Mean}( \pm \mathrm{SD})$ & $772.73( \pm 343.78)$ & $832.26( \pm 388.49)$ & $816.67( \pm 374.11)$ \\
\hline \multicolumn{4}{|l|}{ Laboratory cost (Tk.) } \\
\hline $1000-5000$ & $25(83.3)$ & $34(56.7)$ & $59(65.6)$ \\
\hline $5100-10000$ & $5(16.7)$ & $26(43.3)$ & $31(34.4)$ \\
\hline Total & $30(100.0)$ & $60(100.0)$ & $90(100.0)$ \\
\hline $\operatorname{Mean}( \pm \mathrm{SD})$ & $4823.33( \pm 2096.42)$ & $5367.83( \pm 2361.06)$ & $5186.33( \pm 2279.07)$ \\
\hline \multicolumn{4}{|l|}{ Drug cost } \\
\hline $1000-2000$ & $1(3.3)$ & $7(11.7)$ & $8(8.9)$ \\
\hline $2100-3000$ & $18(60.0)$ & $21(35.0)$ & $39(43.3)$ \\
\hline $3100-4000$ & $9(30.0)$ & $10(16.7)$ & $19(21.1)$ \\
\hline $4100-5000$ & $2(6.7)$ & $11(18.3)$ & $13(14.4)$ \\
\hline $5100-7000$ & $0(0.0)$ & $11(18.3)$ & $11(12.2)$ \\
\hline Total & $30(100.0)$ & $60(100.0)$ & $90(100.0)$ \\
\hline $\operatorname{Mean}( \pm \mathrm{SD})$ & $3086.67( \pm 641.51)$ & $3857.50( \pm 1615.57)$ & $3600.56( \pm 1413.47)$ \\
\hline \multicolumn{4}{|l|}{ Hospital cost } \\
\hline $1000-3000$ & $7(46.7)$ & $19(61.3)$ & $26(56.5)$ \\
\hline $3100-6000$ & $5(33.3)$ & $8(25.8)$ & $13(28.3)$ \\
\hline $6100-9000$ & $3(18.0)$ & $4(12.9)$ & $7(15.2)$ \\
\hline Total & $15(100.0)$ & $31(100.0)$ & $46(100.0)$ \\
\hline $\operatorname{Mean}( \pm \mathrm{SD})$ & $3851.67( \pm 2190.43)$ & $3296.77( \pm 2215.14)$ & $3477.72( \pm 2198.43)$ \\
\hline
\end{tabular}

Table-5: Distribution of the patients by different types of direct costs and cholecystectomy 


\begin{tabular}{|c|c|c|c|}
\hline \multirow{2}{*}{ Types of direct cost } & \multicolumn{2}{|c|}{ Types of cholecystectomy } & \multirow{2}{*}{$\begin{array}{l}\text { Total } \\
\mathrm{f}(\%)\end{array}$} \\
\hline & $\begin{array}{c}\text { Per-abdominal } \\
\mathrm{f}(\%)\end{array}$ & $\begin{array}{c}\text { Laparoscopic } \\
\mathrm{f}(\%)\end{array}$ & \\
\hline \multicolumn{4}{|l|}{ Travel cost } \\
\hline $500-1000$ & $11(36.7)$ & $27(45.0)$ & $38(42.2)$ \\
\hline $1100-2000$ & $16(53.3)$ & $28(46.7)$ & $44(48.9)$ \\
\hline $2100-3000$ & $3(10.0)$ & $5(8.3)$ & $8(8.9)$ \\
\hline Total & $30(100.0)$ & $60(100.0)$ & $90(100.0)$ \\
\hline $\operatorname{Mean}( \pm \mathrm{SD})$ & $1490.00( \pm 542.89)$ & $1405.00( \pm 625.84)$ & $1433.33( \pm 597.75)$ \\
\hline \multicolumn{4}{|l|}{ Food cost (Taka) } \\
\hline $500-1000$ & $11(39.3)$ & $35(59.3)$ & $46(52.9)$ \\
\hline $1100-2000$ & $12(42.9)$ & $17(28.8)$ & $29(33.3)$ \\
\hline $2100-6000$ & $5(17.9)$ & $7(11.9)$ & $12(13.8)$ \\
\hline Total & $28(100.0)$ & $59(100.0)$ & $87(100.0)$ \\
\hline $\operatorname{Mean}( \pm \mathrm{SD})$ & $1734.46( \pm 1341.91)$ & $1232.63( \pm 709.07)$ & $1394.14( \pm 979.81)$ \\
\hline \multicolumn{4}{|l|}{ Attendant's cost (Tk.) } \\
\hline $1000-5000$ & $21(70.0)$ & $38(63.3)$ & $59(65.6)$ \\
\hline $5100-10000$ & $9(30.0)$ & $22(36.7)$ & $31(34.4)$ \\
\hline Total & $30(100.0)$ & $60(100.0)$ & $90(100.0)$ \\
\hline $\operatorname{Mean}( \pm \mathrm{SD})$ & $5000.00( \pm 1860.11)$ & $4714.17( \pm 2319.70)$ & $4809.44( \pm 2170.94)$ \\
\hline
\end{tabular}

Different types of indirect costs incurred by the patients (During last month) and cholecystectomy 
Average income loss was Tk.5833.33( \pm 3685.56$)$ and Tk.5833.33( \pm 3356.59$)$ in perabdominal and laparoscopic group respectively. Majority i.e. $66.7 \%$ patients of perabdominal group and 50.0\% patients of laparoscopic group incurred Tk.3000-5000 income loss.

Average family cost was Tk.6833.33( \pm 4242.64$)$ and Tk.5885.71( $( \pm 4272.04)$ in perabdominal and laparoscopic group respectively. Majority i.e. $44.4 \%$ patients of perabdominal group and $62.0 \%$ patients of laparoscopic group incurred Tk.1000-5000 family cost.

Average tips paid by the patients was Tk.672.22( \pm 185.19$)$ and Tk.691.00( $(243.21)$ in per-abdominal and laparoscopic group respectively. Majority i.e. $77.8 \%$ patients of per-abdominal group and 74.0\% patients of laparoscopic group incurred Tk.500-700. Only 3 patients of laparoscopic group paid unofficial payment. Average unofficial payment was Tk.300.00( \pm 100.00$)$, which are reflected in table-6.

Table-6: Distribution of the patients by different types of indirect costs and cholecystectomy 


\begin{tabular}{|c|c|c|c|}
\hline \multirow{2}{*}{$\begin{array}{l}\text { Types of indirect } \\
\text { cost }\end{array}$} & \multicolumn{2}{|c|}{ Types of cholecystectomy } & \multirow{2}{*}{$\begin{array}{l}\text { Total } \\
\mathrm{f}(\%)\end{array}$} \\
\hline & $\begin{array}{c}\text { Per-abdominal } \\
\mathbb{f} \%)\end{array}$ & $\begin{array}{l}\text { Laparoscopic } \\
\mathbf{f ( \% )}\end{array}$ & \\
\hline \multicolumn{4}{|l|}{ Loss of income (Tk.) } \\
\hline $3000-5000$ & $2(66.7)$ & $3(50.0)$ & $5(55.6)$ \\
\hline $5100-10000$ & $1(33.3)$ & $3(50.0)$ & $4(44.4)$ \\
\hline Total & $3(100.0)$ & $6(100.0)$ & $9(100.0)$ \\
\hline $\operatorname{Mean}( \pm \mathrm{SD})$ & $5833.33( \pm 3685.56)$ & $5833.33( \pm 3356.59)$ & $5833.33( \pm 3230.71)$ \\
\hline \multicolumn{4}{|l|}{ Family cost (Tk.) } \\
\hline $1000-5000$ & $4(44.4)$ & $13(62.0)$ & $17(56.7)$ \\
\hline $5100-10000$ & $3(33.3)$ & $4(19.0)$ & $7(23.3)$ \\
\hline $10100-14000$ & $2(22.2)$ & $4(19.0)$ & $6(20.0)$ \\
\hline Total & $9(100.0)$ & $21(100.0)$ & $30(100.0)$ \\
\hline $\operatorname{Mean}( \pm S D)$ & $6833.33( \pm 4242.64)$ & $5885.71( \pm 4272.04)$ & $6170.00( \pm 4212.72)$ \\
\hline \multicolumn{4}{|c|}{ Tips for treatment (Tk.) } \\
\hline $500-700$ & $21(77.8)$ & $37(74.0)$ & $58(75.3)$ \\
\hline $800-1500$ & $6(22.2)$ & $13(26.0)$ & $19(24.7)$ \\
\hline Total & $27(100.0)$ & $50(100.0)$ & $77(100.0)$ \\
\hline $\operatorname{Mean}( \pm \mathrm{SD})$ & $672.22( \pm 185.19)$ & $691.00( \pm 243.21)$ & $684.42( \pm 223.50)$ \\
\hline \multicolumn{4}{|c|}{ Unofficial payment (Tk.) } \\
\hline 200 & $0(0.0)$ & $1(33.3)$ & $1(33.3)$ \\
\hline 300 & $0(0.0)$ & $1(33.3)$ & $1(33.3)$ \\
\hline 400 & $0(0.0)$ & $1(33.3)$ & $1(33.3)$ \\
\hline Total & $0(0.0)$ & $3(100.0)$ & $3(100.0)$ \\
\hline $\operatorname{Mean}( \pm \mathrm{SD})$ & & $300.00( \pm 100.00)$ & $300.00( \pm 100.00)$ \\
\hline
\end{tabular}

Total treatment costs incurred by the patients (During last month) and cholecystectomy 
Average direct cost was Tk.18228.00( $(4624.75)$ and Tk.18668.30( \pm 5965.67$)$ in perabdominal and laparoscopic group respectively. Majority i.e. $60.0 \%$ patients of perabdominal group and $45.0 \%$ patients of laparoscopic group incurred Tk.15100-25000 direct cost.

Average indirect cost was Tk.3350.00( \pm 4124.58$)$ and Tk.3661.32( \pm 4229.85$)$ in perabdominal and laparoscopic group respectively. Majority i.e. $62.1 \%$ patients of perabdominal group and 58.5\% patients of laparoscopic group incurred Tk.500-2500 indirect cost.

Average treatment cost Tk.21466.30( \pm 6261.42$)$ and Tk.21927.40( \pm 7795.89$)$ in perabdominal and laparoscopic group respectively. Majority i.e. 53.3\% patients of perabdominal group and 51.7\% patients of laparoscopic group incurred Tk.10000-20000 total cost, which are shown in table-7.

Table-7: Distribution of the patients by total treatment costs and cholecystectomy 


\begin{tabular}{|c|c|c|c|}
\hline \multirow{2}{*}{ Attributes } & \multicolumn{2}{|c|}{ Types of cholecystectomy } & \multirow{2}{*}{$\begin{array}{l}\text { Total } \\
\mathrm{f}(\%)\end{array}$} \\
\hline & $\begin{array}{c}\text { Per-abdominal } \\
\mathrm{f}(\%)\end{array}$ & $\begin{array}{l}\text { Laparoscopic } \\
\mathrm{f}(\%)\end{array}$ & \\
\hline \multicolumn{4}{|c|}{ Direct cost (Tk.) } \\
\hline $6500-15000$ & $8(26.7)$ & $25(41.7)$ & $33(36.7)$ \\
\hline $15100-25000$ & $18(60.0)$ & $27(45.0)$ & $45(50.0)$ \\
\hline $25100-35000$ & $4(13.3)$ & $8(13.3)$ & $12(13.3)$ \\
\hline Total & $30(100.0)$ & $60(100.0)$ & $90(100.0)$ \\
\hline $\operatorname{Mean}( \pm \mathrm{SD})$ & $18228.00( \pm 4624.75)$ & $18668.30( \pm 5965.67)$ & $18521.50( \pm 5532.24)$ \\
\hline \multicolumn{4}{|c|}{ Indirect cost (Tk.) } \\
\hline $500-2500$ & $18(62.1)$ & $31(58.5)$ & $49(59.8)$ \\
\hline $2600-5000$ & $4(13.8)$ & $8(15.1)$ & $12(14.6)$ \\
\hline $5100-10000$ & $4(13.8)$ & $8(15.1)$ & $12(14.6)$ \\
\hline $10100-15000$ & $3(10.3)$ & $6(11.30$ & $9(11.0)$ \\
\hline Total & $29(100.0)$ & $53(100.0)$ & $82(100.0)$ \\
\hline $\operatorname{Mean}( \pm \mathrm{SD})$ & $3350.00( \pm 4124.58)$ & $3661.32( \pm 4229.85)$ & $3551.22( \pm 4170.03)$ \\
\hline \multicolumn{4}{|c|}{ Total cost (Tk.) } \\
\hline $10000-20000$ & $16(53.3)$ & $31(51.7)$ & $47(52.2)$ \\
\hline 20100-30000 & $11(36.7)$ & $17(28.3)$ & $28(31.1)$ \\
\hline $30100-39000$ & $3(10.0)$ & $12(20.0)$ & $15(16.7)$ \\
\hline Total & $30(100.0)$ & $60(100.0)$ & $90(100.0)$ \\
\hline $\operatorname{Mean}( \pm \mathrm{SD})$ & $21466.30( \pm 6261.42)$ & $21927.40( \pm 7795.89)$ & $21773.70( \pm 7287.81)$ \\
\hline
\end{tabular}

\section{Basic needs compromised by cholecystectomy}

In per-abdominal group, $15(50.0 \%)$ patients compromised with any basic needs 
among them, 14(93.3\%) patients compromised cost of food, 11(73.3\%) patients compromised cost of clothing, $9(60.0 \%)$ patients compromised cost for treatment of other family members and $3(20.0 \%)$ patients compromised education of other family members.

On the contrary, in laparoscopic group, 24(40.0\%) patients compromised with any basic needs among them, 17(70.0\%) patients compromised cost of food, 11(45.8\%) patients compromised cost of clothing, 13(54.2\%) patients compromised treatment of other family members and 10(41.7\%) patients compromised education of other family members, which are depicted in table-8.

Table-8: Distribution of the patients by compromising basic needs and cholecystectomy

\begin{tabular}{|l|c|c|c|}
\hline \multirow{2}{*}{ Attributes } & \multicolumn{2}{|c|}{ Type of Cholecystectomy } & \multirow{2}{*}{$\begin{array}{c}\text { Total } \\
f(\%)\end{array}$} \\
\cline { 2 - 3 } & $\begin{array}{c}\text { Per-abdominal } \\
\mathrm{f}(\%)\end{array}$ & $\begin{array}{c}\text { Laparoscopic } \\
\mathrm{f}(\%)\end{array}$ & \\
\hline Whether compromise any basic needs & \multicolumn{2}{|c|}{} \\
\hline Yes & $15(50.0)$ & $24(40.0)$ & $39(43.3)$ \\
\hline No & $15(50.0)$ & $36(60.0)$ & $51(56.7)$ \\
\hline Total & $30(100.0)$ & $60(100.0)$ & $90(100.0)$ \\
\hline Which basic needs compromised* & & $17(70.8)$ & $31(79.5)$ \\
\hline Cost of food & $11(73.3)$ & $11(45.8)$ & $22(56.4)$ \\
\hline Cost of clothing & $0(0.0)$ & $3(12.5)$ & $3(7.7)$ \\
\hline Shelter for residing & $9(60.0)$ & $13(54.2)$ & $22(56.4)$ \\
\hline Treatment of other family members & $3(20.0)$ & $10(41.7)$ & $13(33.3)$ \\
\hline Education of family members & & & \\
\hline
\end{tabular}

${ }^{*}$ Multiple responses

\section{Outcome of cholecystectomy of the patients}


The study revealed that in per-abdominal group $86.7 \%$ patients cured after cholecystectomy whereas in laparoscopic group $98.3 \%$ patients cured after cholecystectomy, which are depicted in figure-7.

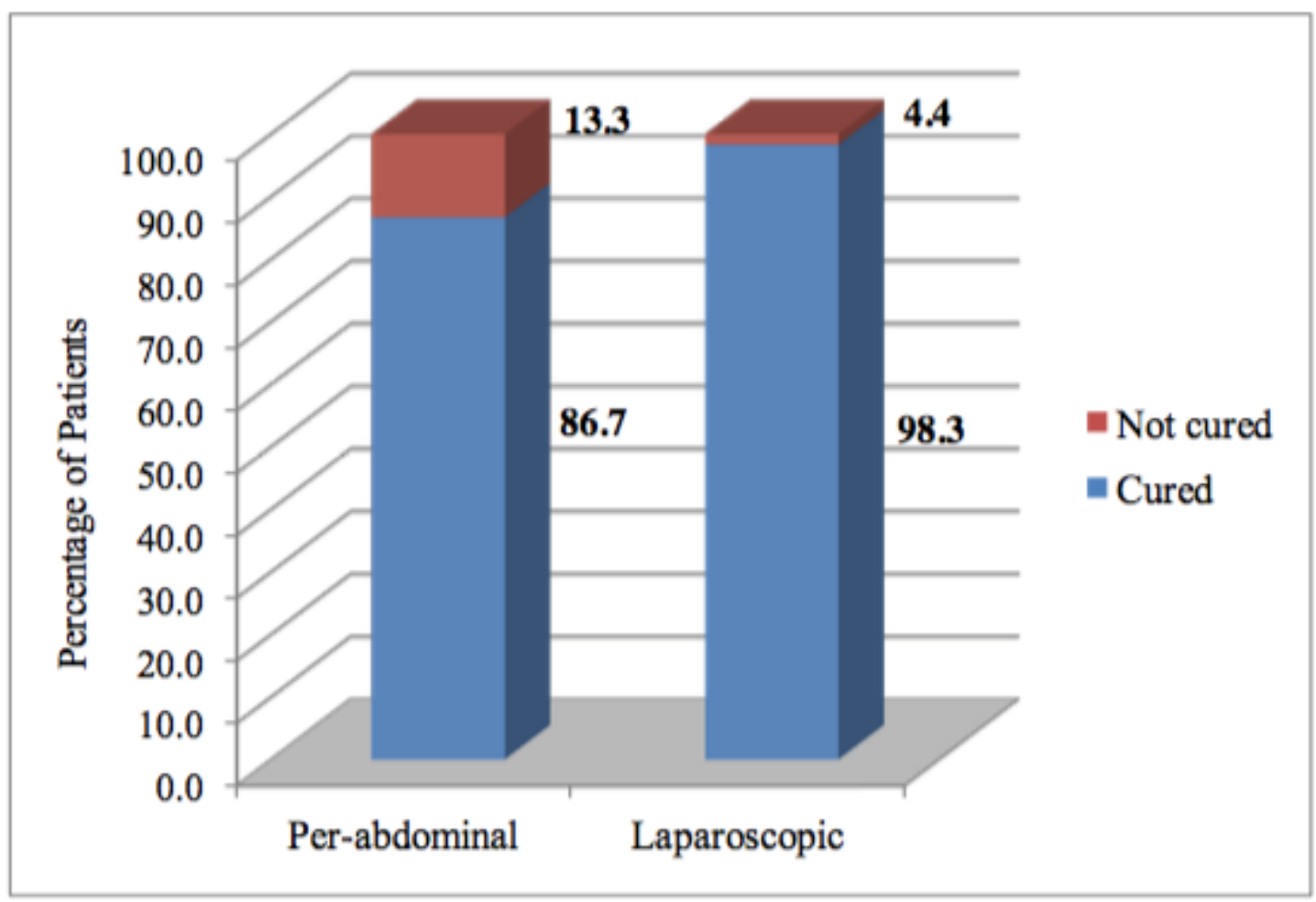

Figure-7: Distribution of the patients by outcome of cholecystectomy

Comparison between average costs by selective socio-demographic attributesisenpi] 
Regarding level of education, among per-abdominal group, average total cost was higher i.e. Tk.26133.00( \pm 9094.25$)$ among secondary level passed patients while lower i.e. Tk.16283.33( \pm 5271.23$)$ among primary level passed patients. But this difference was not statistically significant (ANOVA, $\mathrm{p}>0.05$ ).

On the other hand, among laparoscopic group, average total cost was higher i.e. Tk.23790.00( \pm 10696.85$)$ among primary level passed patients while lower i.e. Tk.20437.50( \pm 8334.73$)$ among HSC passed patients. But this difference was not statistically significant (ANOVA, $\mathrm{p}>0.05$ ).

By occupation, among per-abdominal group, average total cost was higher i.e. Tk.23733.33( \pm 5225.50$)$ among businessmen while lower i.e. Tk.20140.63( \pm 2685.67$)$ among retired persons. But this difference was not statistically significant (ANOVA, $\mathrm{p}>0.05)$.

On the contrary, among laparoscopic group, average total cost was higher i.e. Tk.24480.00( \pm 8417.66$)$ among students while lower i.e. Tk.18150.00( \pm 70.71$)$ among farmers. But this difference was not statistically significant (ANOVA, p>0.05).

In respect of monthly income, among per-abdominal group, average total cost was higher i.e. Tk.25079.00( \pm 6120.83$)$ in the income group Tk.21000-30000 while lower i.e. Tk.19178.57( \pm 6539.49$)$ in the income group Tk.5000-20000. But this difference was not statistically significant (ANOVA, p>0.05).

On the other hand, among laparoscopic group, average total cost was higher i.e. Tk.22824.62 $( \pm 8012.48)$ in the income group Tk.31000-50000 while lower i.e. Tk.21507.35( \pm 7452.99$)$ in the income group Tk.21000-30000. But this difference was not statistically significant (ANOVA, $\mathrm{p}>0.05$ ), which are depicted in table-9.

Table-9: Comparison between average costs by selective socio-demographic attributes 


\begin{tabular}{|c|c|c|c|c|}
\hline \multirow{3}{*}{ Attributes } & \multicolumn{4}{|c|}{ Types of cholecystectomy } \\
\hline & \multicolumn{2}{|c|}{ Per-abdominal } & \multicolumn{2}{|c|}{ Laparoscopic } \\
\hline & $\begin{array}{c}\text { Total cost (Tk.) } \\
\text { Mean } \pm \mathrm{SD}\end{array}$ & $\begin{array}{l}\text { Significance } \\
\text { (ANOVA) }\end{array}$ & $\begin{array}{c}\text { Total cost (Tk.) } \\
\text { MeantSD } \\
\end{array}$ & $\begin{array}{l}\text { Significance } \\
\text { (ANOVA) }\end{array}$ \\
\hline \multicolumn{5}{|c|}{ Level of education } \\
\hline Illiterate & $21187.50( \pm 5527.51)$ & \multirow{7}{*}{$\begin{array}{l}F=1.34 \\
d f=4 \\
p=0.28\end{array}$} & $21381.25( \pm 7577.83)$ & \multirow{7}{*}{$\begin{array}{l}F=0.17 \\
d f=6 \\
p=0.99\end{array}$} \\
\hline Primary & $16283.33( \pm 5271.23)$ & & $23790.00( \pm 10696.85)$ & \\
\hline Secondary & $26133.00( \pm 9094.25)$ & & $21607.69( \pm 7230.09)$ & \\
\hline SSC & $19375.00( \pm 2227.39)$ & & $22425.00( \pm 3712.31)$ & \\
\hline HSC & - & & $20437.50( \pm 8334.73)$ & \\
\hline Honors & $22175.00( \pm 5055.81)$ & & $22015.63( \pm 5397.11)$ & \\
\hline Masters & & & $23423.33( \pm 12197.28)$ & \\
\hline \multicolumn{5}{|l|}{ Occupation } \\
\hline Student & $18600.00()$. & \multirow{7}{*}{$\begin{array}{l}F=0.54 \\
d f=4 \\
p=0.71\end{array}$} & $24480.00( \pm 8417.66)$ & \multirow{7}{*}{$\begin{array}{l}\mathrm{F}=0.59 \\
\mathrm{df}=6 \\
\mathrm{p}=0.74\end{array}$} \\
\hline Service & - & & $21075.00( \pm 7553.20)$ & \\
\hline Business & $23733.33( \pm 5225.50)$ & & $21525.00( \pm 6618.85)$ & \\
\hline Agriculture & - & & $18150.00( \pm 70.71)$ & \\
\hline Day Labor & $15000.00()$. & & $10000.00()$. & \\
\hline Housewife & $22239.12( \pm 7673.79)$ & & $22559.52( \pm 8448.18)$ & \\
\hline Retired & $20140.63( \pm 2685.67)$ & & $21397.50( \pm 7173.63)$ & \\
\hline \multicolumn{5}{|c|}{ Monthly income (Tk.) } \\
\hline $\begin{array}{l}5000- \\
20000\end{array}$ & $19178.57( \pm 6539.49)$ & \multirow{3}{*}{$\begin{array}{l}\mathrm{F}=2.99 \\
\mathrm{df}=2 \\
\mathrm{p}=0.07\end{array}$} & $21776.67( \pm 8120.81)$ & \multirow{3}{*}{$\begin{array}{l}F=0.11 \\
d f=2 \\
p=0.89\end{array}$} \\
\hline $\begin{array}{l}21000- \\
30000\end{array}$ & $25079.00( \pm 6120.83)$ & & $21507.35( \pm 7452.99)$ & \\
\hline $\begin{array}{l}31000- \\
50000 \\
\end{array}$ & $20783.33( \pm 2729.23)$ & & $22824.62( \pm 8012.48)$ & \\
\hline
\end{tabular}

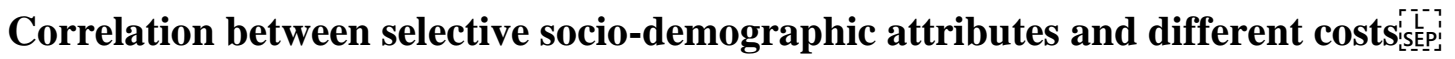

The study revealed that in per-abdominal group total cost and indirect cost were 
proportionately correlated whereas direct cost was inversely correlated with age of the patients, but these were not statistically significant (correlation, $\mathrm{p}>0.05$ ). On the other hand, in laparoscopic group total cost as well as direct and indirect cost were inversely correlated with age of the patients, but these were not statistically significant (correlation, $\mathrm{p}>0.05$ ).

It was also found that in per-abdominal group total cost and direct cost were proportionately correlated with monthly income of the patients while indirect cost was inversely correlated with monthly income but these were not statistically significant (correlation, $\mathrm{p}>0.05$ ). On the contrary in laparoscopic group total cost as well as direct and indirect cost were correlated with monthly income of the patients, but these were not statistically significant (correlation, $\mathrm{p}>0.05$ ), which are shown in table-10.

Table-10: Correlation between selective socio-demographic attributes and different costs 


\begin{tabular}{|c|c|c|c|c|c|c|c|c|c|c|}
\hline \multicolumn{11}{|c|}{ Per-abdominal group } \\
\hline \multirow[t]{2}{*}{ Attributes } & \multicolumn{2}{|c|}{ Age (Yrs) } & \multicolumn{2}{|c|}{$\begin{array}{c}\text { Monthly } \\
\text { income (TK.) }\end{array}$} & \multicolumn{2}{|c|}{$\begin{array}{l}\text { Direct cost } \\
\text { (Tk.) }\end{array}$} & \multicolumn{2}{|c|}{$\begin{array}{l}\text { Indirect } \\
\text { Cost (Tk.) }\end{array}$} & \multicolumn{2}{|c|}{$\begin{array}{l}\text { Total Cost } \\
\text { (Tk.) }\end{array}$} \\
\hline & $\mathrm{r}$ & $\mathrm{p}$ & $\mathrm{r}$ & $\mathrm{p}$ & $\mathrm{r}$ & $\mathrm{p}$ & $\mathrm{r}$ & $\mathrm{p}$ & $\mathrm{r}$ & $\mathrm{p}$ \\
\hline Age (Yrs) & 1 & & 0.04 & 0.82 & -0.08 & 0.68 & 0.17 & 0.38 & 0.04 & 0.84 \\
\hline $\begin{array}{l}\text { Monthly } \\
\text { income (Tk.) }\end{array}$ & 0.04 & 0.82 & 1 & & 0.31 & 0.10 & -0.05 & 0.80 & 0.19 & 0.33 \\
\hline $\begin{array}{l}\text { Direct cost } \\
\text { (Tk.) }\end{array}$ & -0.08 & 0.68 & 0.31 & 0.10 & 1 & & 0.05 & 0.82 & $0.76^{*}$ & 0.00 \\
\hline $\begin{array}{l}\text { Indirect Cost } \\
\text { (Tk.) }\end{array}$ & 0.17 & 0.38 & -0.05 & 0.80 & 0.05 & 0.82 & 1 & & $0.68^{* *}$ & 0.00 \\
\hline $\begin{array}{l}\text { Total Cost } \\
\text { (Tk.) }\end{array}$ & 0.04 & 0.84 & 0.19 & 0.33 & $0.76^{*}$ & 0.00 & $0.68^{* *}$ & 0.00 & 1 & \\
\hline \multicolumn{11}{|c|}{ Laparoscopic group } \\
\hline \multirow[t]{2}{*}{ Attributes } & \multicolumn{2}{|c|}{ Age (Yrs) } & \multicolumn{2}{|c|}{$\begin{array}{c}\text { Monthly } \\
\text { income (Tk.) }\end{array}$} & \multicolumn{2}{|c|}{$\begin{array}{l}\text { Direct cost } \\
\text { (Tk.) }\end{array}$} & \multicolumn{2}{|c|}{$\begin{array}{c}\text { Indirect } \\
\text { Cost (Tk.) }\end{array}$} & \multicolumn{2}{|c|}{$\begin{array}{l}\text { Total Cost } \\
\text { (Tk.) }\end{array}$} \\
\hline & $\mathrm{r}$ & $\mathrm{p}$ & $\mathrm{r}$ & $\mathrm{p}$ & $\mathrm{r}$ & $p$ & $r$ & $p$ & $\mathrm{r}$ & $p$ \\
\hline Age (Yrs) & 1 & & 0.14 & 0.30 & -0.04 & 0.76 & -0.22 & 0.11 & -0.18 & 0.18 \\
\hline $\begin{array}{l}\text { Monthly } \\
\text { income (Tk.) }\end{array}$ & 0.14 & 0.30 & 1 & & 0.13 & 0.33 & 0.01 & 0.92 & 0.10 & 0.46 \\
\hline $\begin{array}{l}\text { Direct cost } \\
\text { (Tk.) }\end{array}$ & -0.04 & 0.76 & 0.13 & 0.33 & 1 & & 0.18 & 0.20 & $0.85^{* *}$ & 0.00 \\
\hline $\begin{array}{l}\text { Indirect Cost } \\
\text { (Tk.) }\end{array}$ & -0.22 & 0.11 & 0.01 & 0.92 & 0.18 & 0.20 & 1 & & $0.68^{* *}$ & 0.00 \\
\hline $\begin{array}{l}\text { Total cost } \\
\text { (Tk.) }\end{array}$ & -0.18 & 0.18 & 0.10 & 0.46 & $0.85^{*}$ & 0.00 & $0.68^{*}$ & 0.00 & 1 & \\
\hline
\end{tabular}

\section{Correlation between different costs and duration of disease and hospital stay:sep:}

The study showed that in per-abdominal group total cost, direct cost and indirect cost correlated with duration of disease, but these were not statistically significant 
(correlation, $\mathrm{p}>0.05)$. On the other hand, in laparoscopic group also total cost, direct cost and indirect cost correlated with duration of disease, but these were not statistically significant (correlation, $\mathrm{p}>0.05$ ).

It was revealed that in per-abdominal group total cost as well as direct cost correlated with hospital stay and these were statistically significant (correlation, $\mathrm{p}<0.01$ ) whereas indirect cost also correlated with hospital stay and it was statistically significant (correlation, $\mathrm{p}<0.05)$. On the other hand, in laparoscopic group total cost as well as direct and indirect cost correlated with hospital stay and these were statistically significant (correlation, $\mathrm{p}<0.01$ ), which are documented in table-11.

Table-11: Correlation of different costs with duration of disease and hospital stay by cholecystectomy 


\begin{tabular}{|c|c|c|c|c|c|c|c|c|c|c|}
\hline \multicolumn{11}{|c|}{ Per-abdominal cholecystectomy } \\
\hline \multirow[t]{2}{*}{ Attributes } & \multicolumn{2}{|c|}{$\begin{array}{l}\text { Duration of } \\
\text { disease } \\
\text { (Month) }\end{array}$} & \multicolumn{2}{|c|}{$\begin{array}{l}\text { Hospital stay } \\
\text { (Day) }\end{array}$} & \multicolumn{2}{|c|}{$\begin{array}{l}\text { Direct cost } \\
\text { (Tk.) }\end{array}$} & \multicolumn{2}{|c|}{$\begin{array}{l}\text { Indirect Cost } \\
\text { (Tk.) }\end{array}$} & \multicolumn{2}{|c|}{$\begin{array}{c}\text { Total Cost } \\
\text { (Tk.) }\end{array}$} \\
\hline & $\mathrm{r}$ & $\mathrm{p}$ & $\mathrm{r}$ & $\mathrm{p}$ & $\mathrm{r}$ & $\mathrm{p}$ & $\mathrm{r}$ & $\mathrm{p}$ & $\mathrm{r}$ & $\mathrm{p}$ \\
\hline $\begin{array}{l}\text { Duration } \\
\text { of disease } \\
\text { (Month) }\end{array}$ & 1 & & 0.21 & 0.27 & 0.23 & 0.22 & 0.12 & 0.55 & 0.25 & 0.19 \\
\hline $\begin{array}{l}\text { Hospital } \\
\text { stay (Day) }\end{array}$ & 0.21 & 0.27 & 1 & & $0.63^{* *}$ & 0.00 & $0.38^{\circ}$ & 0.04 & $0.71^{* *}$ & 0.00 \\
\hline $\begin{array}{l}\text { Direct cost } \\
\text { (Tk.) }\end{array}$ & 0.23 & 0.22 & $0.63^{*}$ & 0.00 & 1 & & 0.05 & 0.82 & $0.76^{* *}$ & 0.00 \\
\hline $\begin{array}{l}\text { Indirect } \\
\text { Cost (Tk.) }\end{array}$ & 0.12 & 0.55 & $0.38^{\circ}$ & 0.04 & 0.05 & 0.82 & 1 & & $0.68^{* *}$ & 0.00 \\
\hline $\begin{array}{l}\text { Total Cost } \\
\text { (Tk.) }\end{array}$ & 0.25 & 0.19 & $0.72^{* *}$ & 0.00 & $0.76^{* *}$ & 0.00 & $0.68^{* *}$ & 0.00 & 1 & \\
\hline \multicolumn{11}{|c|}{ Laparoscopic cholecystectomy } \\
\hline \multirow[t]{2}{*}{ Attributes } & \multicolumn{2}{|c|}{$\begin{array}{c}\text { Duration of } \\
\text { disease } \\
\text { (Months) }\end{array}$} & \multicolumn{2}{|c|}{$\begin{array}{l}\text { Hospital stay } \\
\text { (Days) }\end{array}$} & \multicolumn{2}{|c|}{$\begin{array}{l}\text { Direct cost } \\
\text { (Tk.) }\end{array}$} & \multicolumn{2}{|c|}{$\begin{array}{l}\text { Indirect Cost } \\
\text { (Tk.) }\end{array}$} & \multicolumn{2}{|c|}{$\begin{array}{c}\text { Total Cost } \\
\text { (Tk.) }\end{array}$} \\
\hline & $\mathrm{r}$ & $\mathrm{p}$ & $\mathrm{r}$ & $\mathrm{p}$ & $r$ & $\mathrm{p}$ & $\mathrm{r}$ & $\mathrm{p}$ & $\mathrm{r}$ & $\mathrm{p}$ \\
\hline $\begin{array}{l}\text { Duration } \\
\text { of disease } \\
\text { (Month) }\end{array}$ & 1 & & 0.03 & 0.81 & 0.10 & 0.44 & 0.08 & 0.56 & 0.13 & 0.32 \\
\hline $\begin{array}{l}\text { Hospital } \\
\text { stay (Day) }\end{array}$ & 0.03 & 0.81 & 1 & & $0.44^{* *}$ & 0.00 & 0.19 & 0.17 & $0.45^{* *}$ & 0.00 \\
\hline $\begin{array}{l}\text { Direct cost } \\
\text { (Tk.) }\end{array}$ & 0.10 & 0.44 & $0.44^{*}$ & 0.00 & 1 & & 0.18 & 0.20 & $0.85^{* *}$ & 0.00 \\
\hline $\begin{array}{l}\text { Indirect } \\
\text { Cost (Tk.) }\end{array}$ & 0.08 & 0.56 & 0.19 & 0.17 & 0.18 & 0.20 & 1 & & $0.68^{* *}$ & 0.00 \\
\hline $\begin{array}{l}\text { Total Cost } \\
\text { (Tk.) }\end{array}$ & 0.13 & 0.32 & $0.45^{\circ *}$ & 0.00 & $0.85^{* *}$ & 0.00 & $0.68^{* *}$ & 0.00 & 1 & \\
\hline \multicolumn{11}{|c|}{$*$. Correlation is significant at the 0.01 level (2-tailed). } \\
\hline$\bullet$ Correla & $\mathrm{s} s$ & fica & t the 0 & $05 \mathrm{le}$ & (2-ta & & & & & \\
\hline
\end{tabular}

\section{Linear regression between total cost and duration of hospital stay}


Linear regression showed that among per-abdominal group, total cost proportionate to hospital stay $\left(\mathrm{R}^{2}=0.506\right)$. Whereas among laparoscopic group, total cost also proportionate to hospital stay $\left(\mathrm{R}^{2}=0.200\right)$. Total cost was increased when duration of hospital stay increase in both the groups, which are depicted in figure- $8 \& 9$.

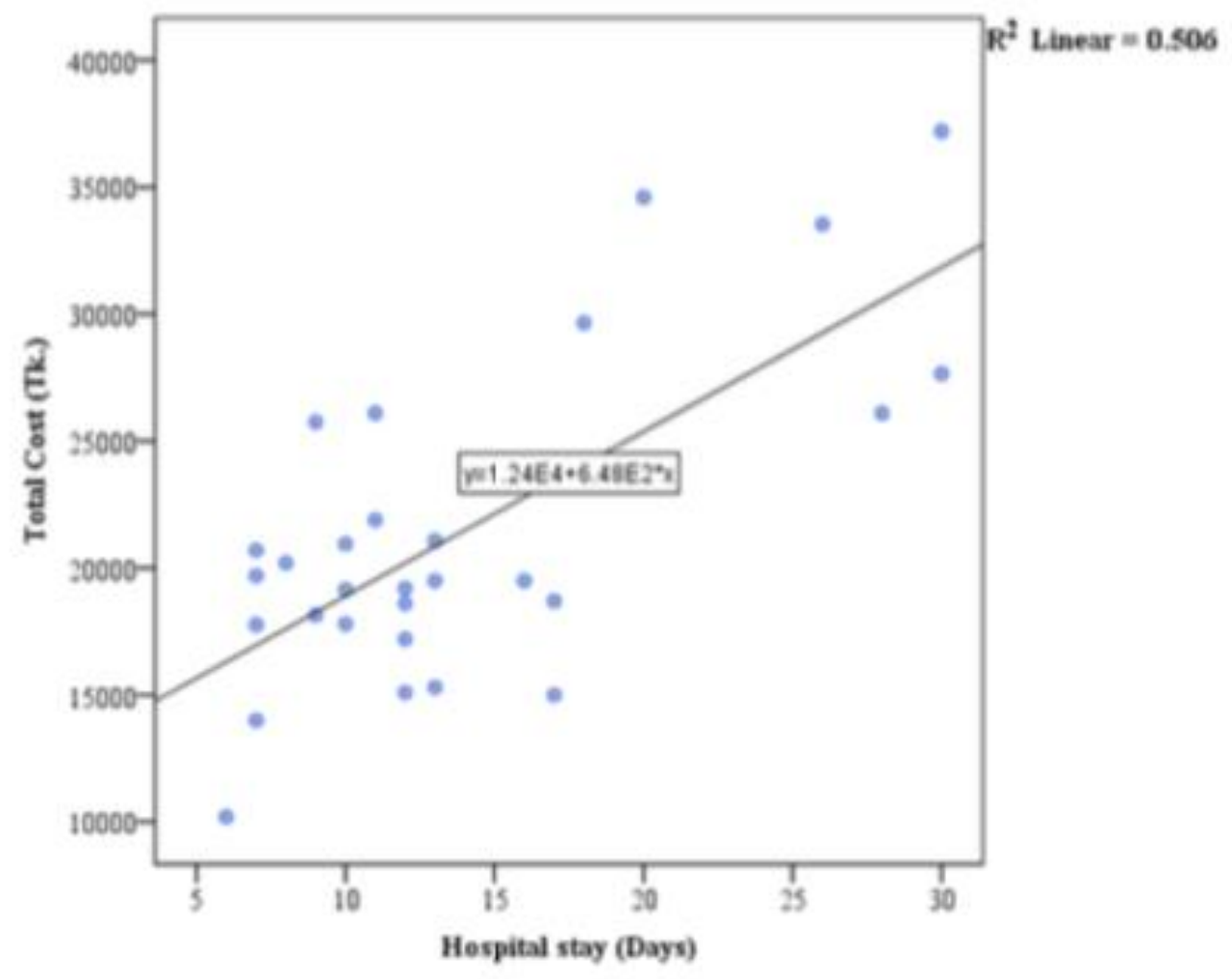

Figure-8: Linear regression between total cost and duration of hospital stay in per-abdominal cholecystectomy group 


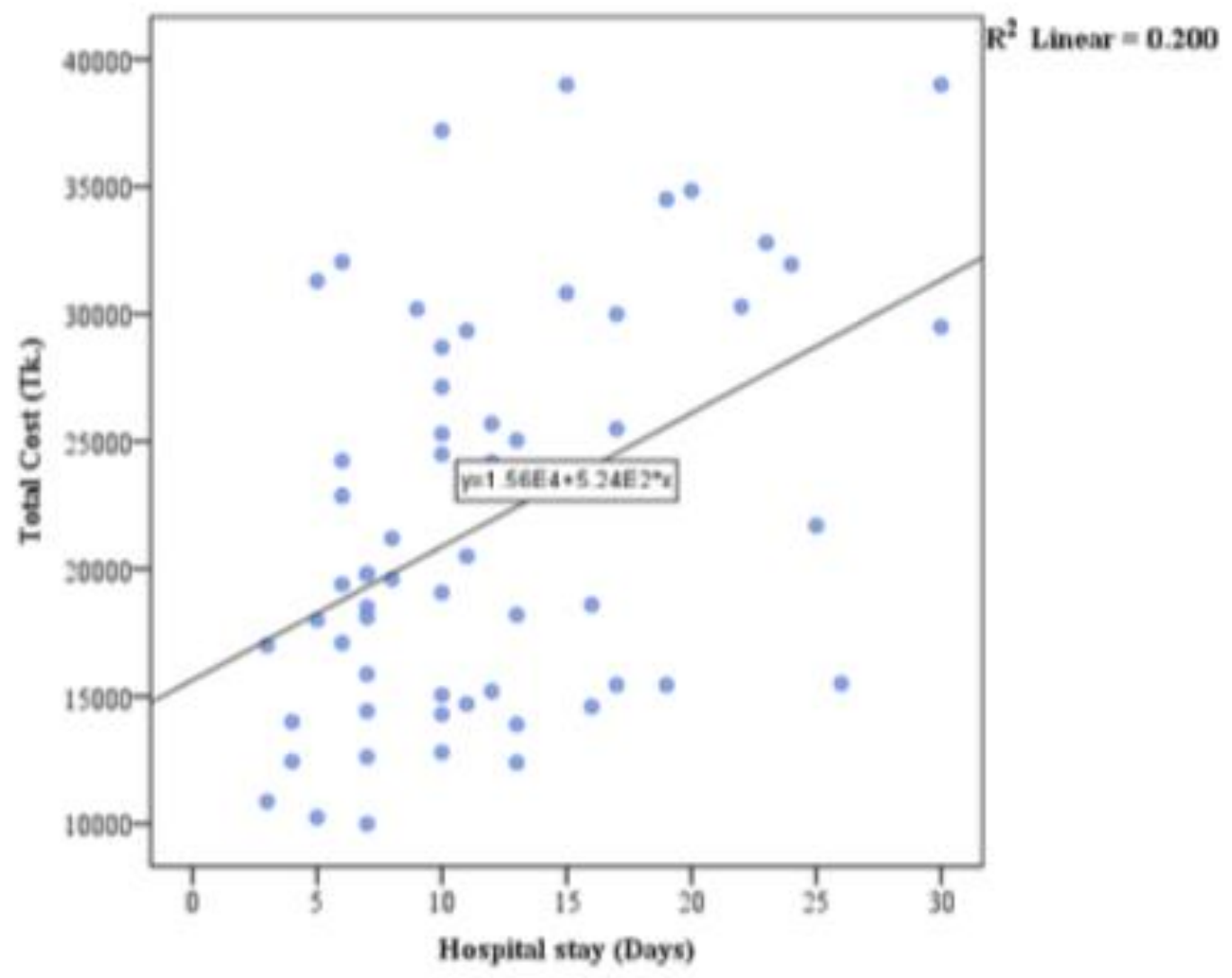

Figure-9: Linear regression between total cost and duration of hospital stay in laparoscopic cholecystectomy group

\section{Linear regression between direct cost and duration of hospital stay}

Linear regression showed that among per-abdominal group, direct cost proportionate to hospital stay $\left(\mathrm{R}^{2}=0.398\right)$. While among laparoscopic group, direct cost proportionate to hospital stay $\left(\mathrm{R}^{2}=0.196\right)$. Direct cost was increased in response to hospital stay increase in both the groups, which are depicted in figure-10 \& 11 . 


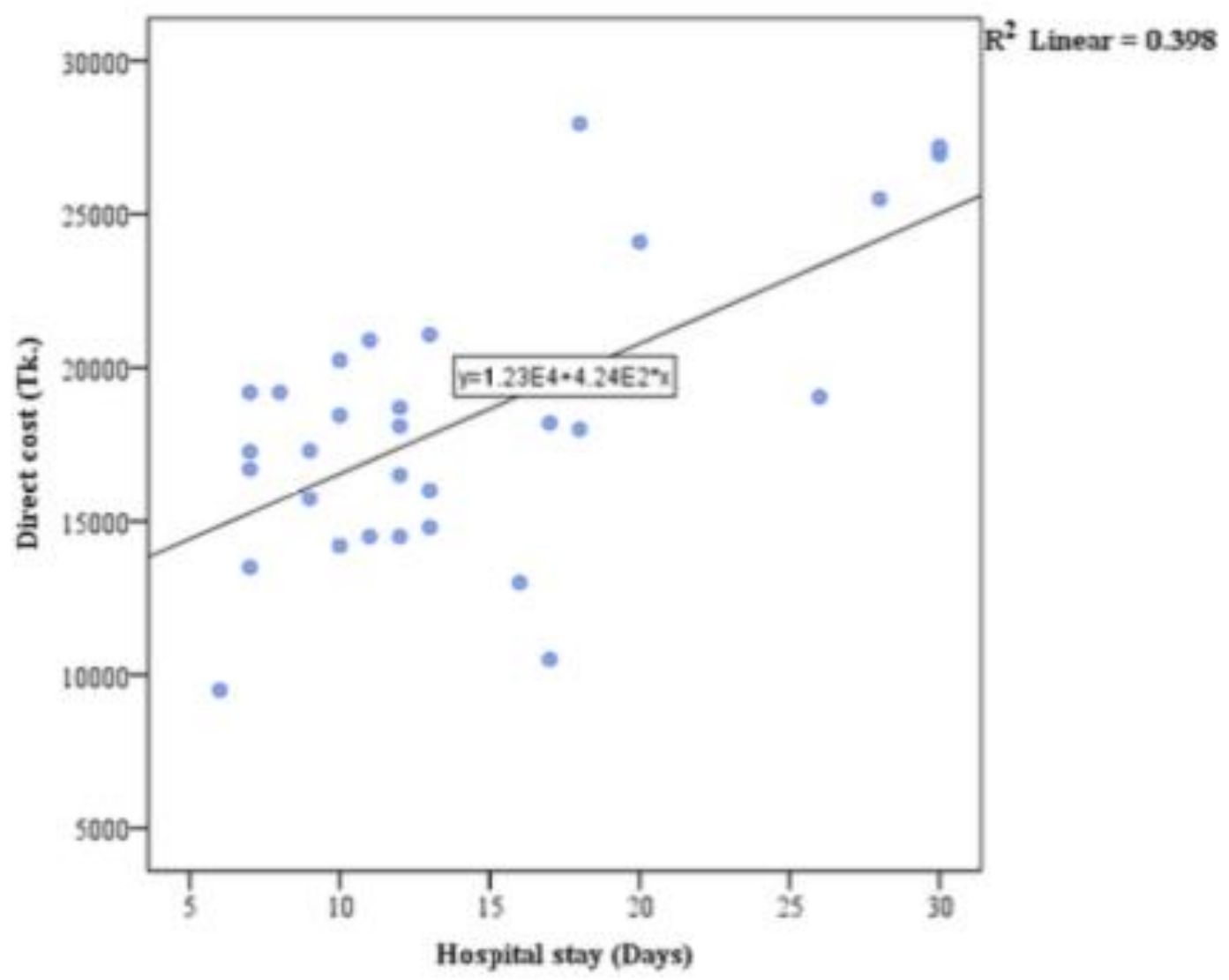

Figure-10: Linear regression between direct cost and duration of hospital stay in per-abdominal cholecystectomy group 


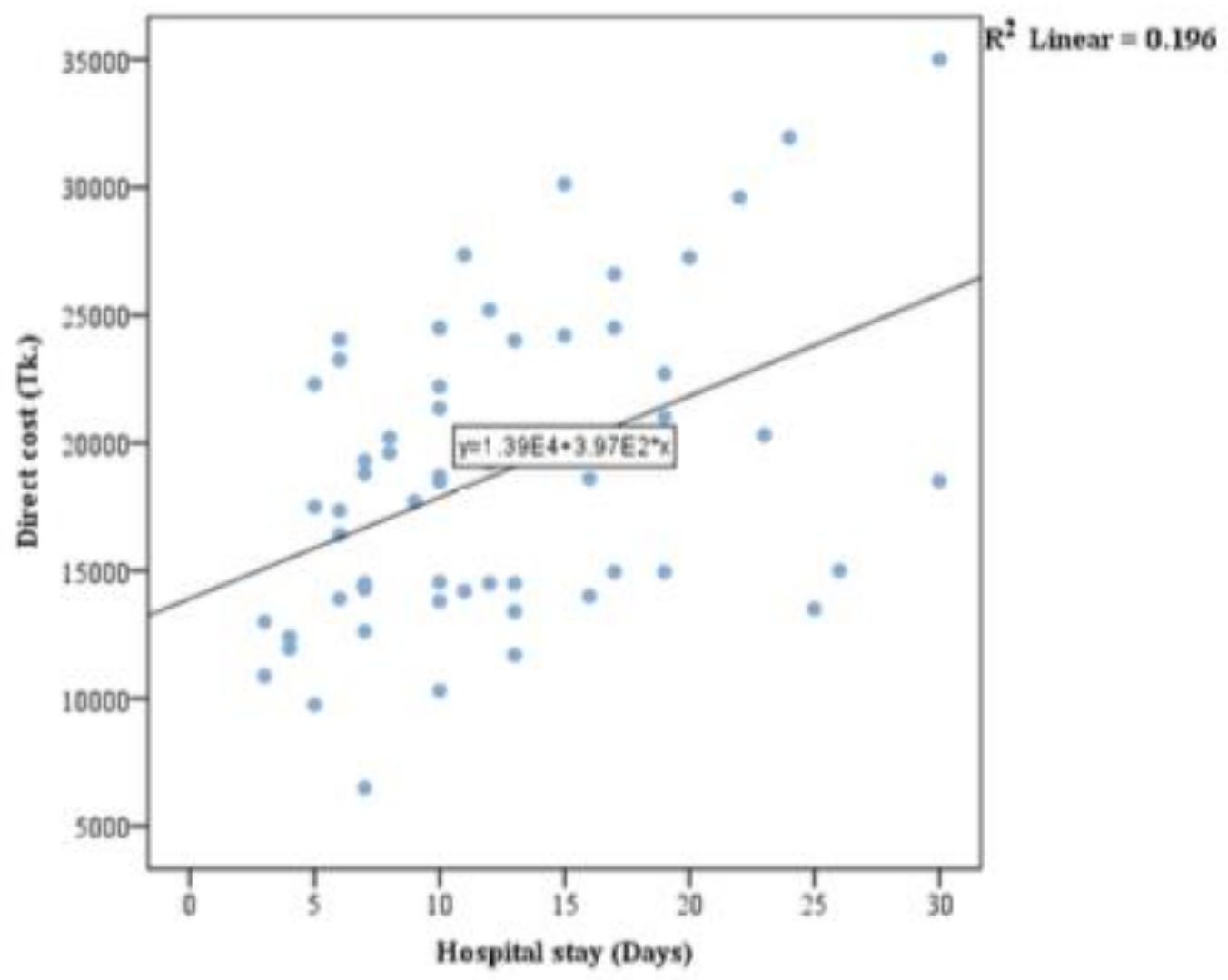

Figure-11: Linear regression between direct cost and duration of hospital stay in laparoscopic cholecystectomy group

\section{Linear regression between indirect cost and duration of hospital stay}

Linear regression revealed that among per-abdominal group, indirect cost proportionate to hospital stay $\left(\mathrm{R}^{2}=0.141\right)$. Whereas among laparoscopic group, total cost also proportionate to hospital stay $\left(\mathrm{R}^{2}=0.037\right)$. Indirect cost was increased in response to hospital stay increase in both groups, which are shown in figure-12 \&13. 


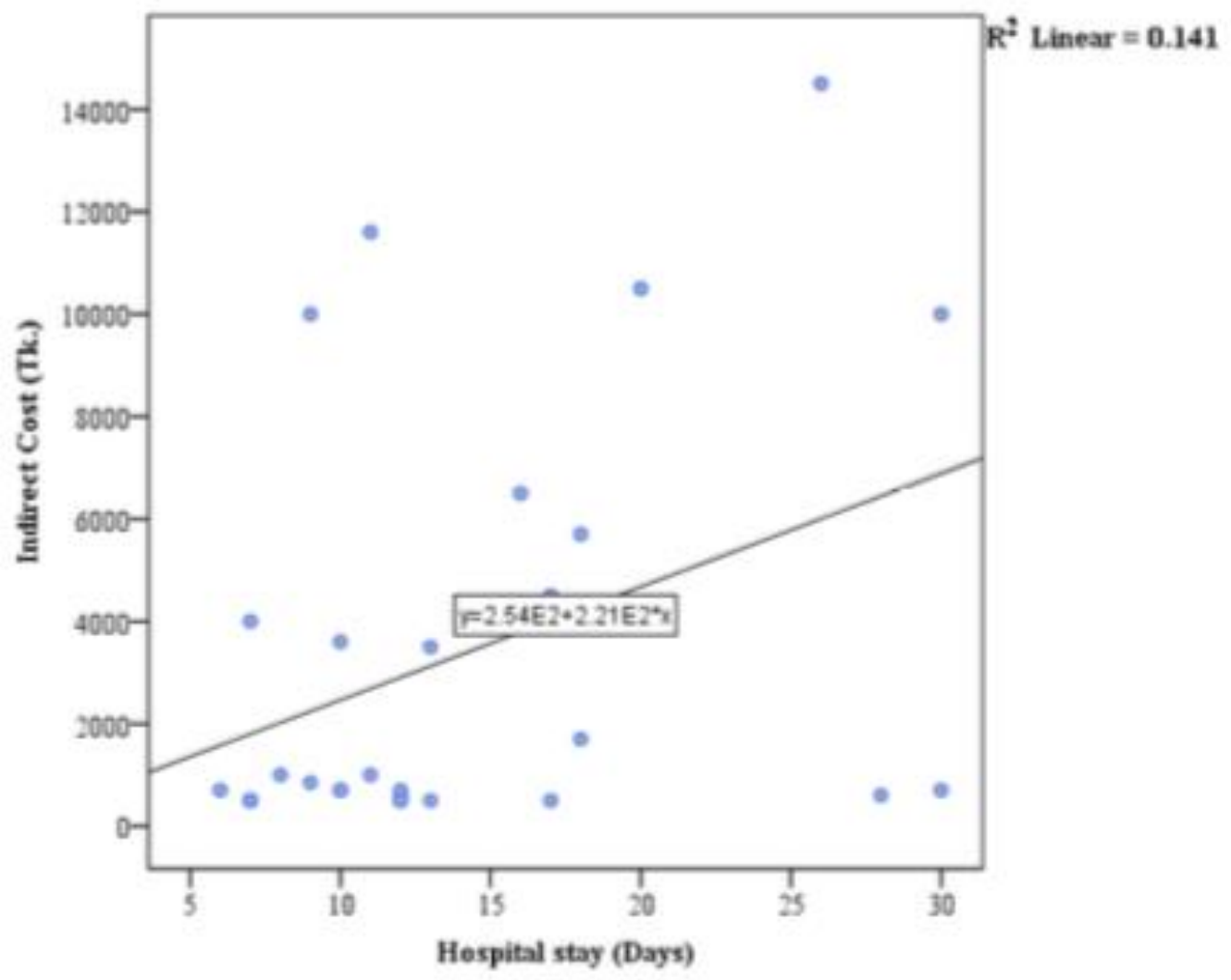

Figure-12: Linear regression between indirect cost and duration of hospital stay in per-abdominal cholecystectomy group 


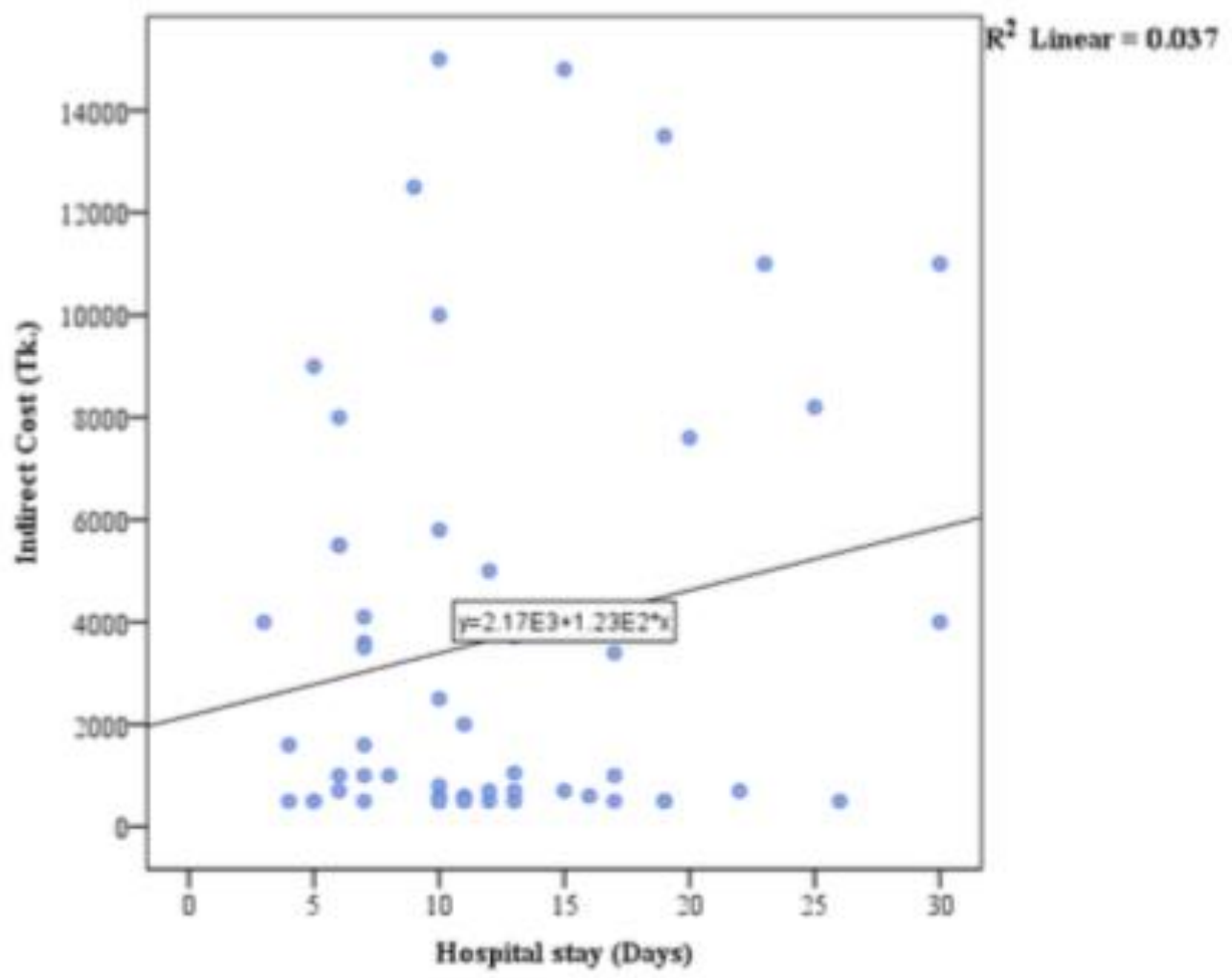

Figure-13: Linear regression between indirect cost and duration of hospital stay in laparoscopic cholecystectomy group 


\section{Discussion}

This comparative cross sectional study was conducted among 90 cholecystectomised patients among them 30 patients underwent per-abdominal cholecystectomy and 60 patients underwent laparoscopic cholecystectomy to assess the cost-effectiveness of per-abdominal and laparoscopic cholecystectomy. The study also determine sociodemographic characteristics of the patients along with estimation of costs both direct and indirect incurred by the patients, determine the outcome and compare cost per unit of benefit (patient cured) between per-abdominal and laparoscopic cholecystectomy. The study findings were compared with findings of other relevant studies and logically/scientifically argued as follows.

\section{Socio-demographic characteristics of the cholecystectomy patients}

The study revealed that in both per-abdominal and laparoscopic group, females (76.7\%) and males (23.3\%). A similar finding was found in a study where $82 \%$ patients were females and $18 \%$ patients were males (Shukla, A. et al., 2017). In another study it has been documented that females are more prone to develop cholelithiasis (Volzke, H. et al., 2005)

In this study age of patients ranged from 20 to 69 years. About $40 \%$ patients were in the age group 20-39 years followed by $43.3 \%$ were in the age group $40-59$ years and the rest $16.7 \%$ were in the age group 60-69 years. The average age of the patients was $42.94( \pm 13.50)$ years. This finding was quite similar with another study where $65 \%$ patients of laparoscopic surgery were in the age group 20 - 39 years, whereas $62 \%$ patients of open cholecystectomy were in the age group 40 - 59 yrs (Rahman, M.S. et al., 2015). Finding of this particular study was quite similar with another study where age of patients ranged from 20 to 70 years and mean age was $41.30( \pm 12.01)$ years in both the groups (Shukla, A. et al., 2017).

In this study among per-abdominal group, majority i.e. $60.0 \%$ patients were illiterate, followed by $10.0 \%$ patients had primary level education, $16.7 \%$ patients had secondary level education. On the other hand, among laparoscopic group, majority i.e. $26.7 \%$ patients were illiterate, followed by $16.7 \%$ patients had primary level education, $21.7 \%$ patients had secondary level education. Similar findings were reported in a study that nearly $61 \%$ of the patients were illiterate and the remaining included primary $(14.6 \%)$, middle $(8.5 \%)$, secondary (4.9\%) and post-secondary 
(10.9\%) education (Naeem, M. et al., 2012).

By occupation, there were more or less the same proportion of housewives in both per-abdominal and laparoscopic group but proportion of students and service holders were more in laparoscopic group than per-abdominal group and proportion of businessmen, day laborer and retired persons were more in per-abdominal group than laparoscopic group. Regarding monthly income, nearly half of the patients were in Tk.5000-20000 income group in both per-abdominal and laparoscopic group. Average monthly income was Tk.23200.00( \pm 12374.61$)$ in per-abdominal group while it was Tk.24925.00( \pm 12166.86$)$ in laparoscopic group. This difference can be explained by the fact that laparoscopic cholecystectomy was costly than per-abdominal cholecystectomy. So, economically more solvent patients preferred laparoscopic method whereas low income patients preferred per-abdominal method. In a study conducted in Pakistan showed that All of the patients were from low socioeconomic status; therefore, the mean $( \pm$ SD) salary was PKR.6915( \pm 1992$)$ (Naeem, M. et al., 2012).

In this study among per-abdominal group, $86.7 \%$ patients were Muslims and $13.3 \%$ were Hindus while among laparoscopic group, 90.0\% patients were Muslims and $10.0 \%$ were Hindus, These findings were not consistent with the country scenario as found by BBS where Muslims were Hindu around $90.39 \%$ and $8.54 \%$ respectively (BBS, 2017). These differences may due to the fact that this study was conducted in patients undergo cholecystectomy in three government hospitals of Dhaka city while the survey of BBS was carried out countrywide with larger population. In this study among per-abdominal group, $70.0 \%$ patients were married followed by $26.7 \%$ were widow/widower and $3.3 \%$ unmarried, but the corresponding figure among laparoscopic group were about $85.0 \%, 8.3 \%$ and $6.7 \%$ respectively. This can be explained by the facts that majority of the patients in per-abdominal group were elder in comparison to the laparoscopic group as a result, proportion of widow/widower people was comparatively larger and unmarried patients were relatively smaller in the per-abdominal group than in the laparoscopic group. A Pakistani study showed significant association between marital status and gallstone occurrence, as $95.1 \%$ of their study subjects were married (Naeem, M. et al., 2012).

By residing place, among per-abdominal group, 53.3\% patients were from urban areas and $46.7 \%$ were from rural areas. On the other hand, among laparoscopic group, $51.7 \%$ patients were from urban areas and $48.3 \%$ were from rural areas. This finding 
differed with the finding of BBS where more than $71.9 \%$ population lived in rural areas (BBS, 2017). This can be explained with the realities that BBS calculated population in country perspective while this study conducted among selective patients underwent per-abdominal and laparoscopic cholecystectomy. In this study among perabdominal group, $20.0 \%$ patients lived in pucca house, $46.7 \%$ lived in semi-pucca house and 33.3\% lived in kacha house while among laparoscopic group, 38.3\% patients lived in pucca house, $41.7 \%$ lived in semi-pucca house and $20.0 \%$ lived in kancha house. By family type, among per-abdominal group, majority i.e. 53.3\% patients were from nuclear family and the rest $46.7 \%$ were from joint family but among laparoscopic group, four-fifths patients were from nuclear family and the rest were from joint family. Average family size was $5.17( \pm 1.86)$ in per-abdominal group while it was $4.88( \pm 1.92)$ in laparoscopic group. This finding was different with the finding of BBS where the average family size was found 4.5. This can be explained by the facts that BBS calculated family size in country perspective while in this study family size was calculated from selective patients (BBS, 2017).

\section{Treatment of cholelithiasis}

The study revealed that about $53.3 \%$ patients in per-abdominal group and $70.0 \%$ patients of laparoscopic group were suffering from cholelithiasis for 1-6 months. However, average duration of suffering from cholelithiasis was $9.50( \pm 8.68)$ months in per-abdominal group and $12.43( \pm 17.49)$ months in laparoscopic group. Among perabdominal group, $56.7 \%$ patients were diagnosed at government hospitals followed by $30.0 \%$ patients at private hospitals. On the other hand, among laparoscopic group, $58.3 \%$ patients were diagnosed at private hospitals followed by $31.7 \%$ patients at government hospitals. About $63.3 \%$ patients of per-abdominal group took treatment from government hospital and $23.3 \%$ patients took from private hospital for first time whereas $43.3 \%$ patients of laparoscopic group took treatment from government hospital and $46.7 \%$ patients took from private hospital. This difference was explained by the facts that knowledge, awareness about the treatment and economic solvency varies from person to person. Regarding hospital stay, among per-abdominal group, $50.0 \%$ patients were in 8-14 days group and 33.3\% were in 15-30 days group while

among laparoscopic group, 36.7\% patients were in 8-14 days group and 33.3\% were in 3-7 days group. Average duration of hospital stay was $13.97( \pm 6.88)$ days in perabdominal group while it was $12.02( \pm 6.66)$ days in laparoscopic group. It was comparable with another study conducted by Talpur, K.A.H. et al. where hospital stay 
ranged from 3-30 days in per-abdominal cholecystectomy and 1-20 days in laparoscopic cholecystectomy with average length of hospitalization was $5.56 \pm 2.98$ days in per-abdominal group and $3.02 \pm 1.75$ days in laparoscopic group. The difference of mean can be explained by the facts that the study of Talpur, K.A.H. et al. was conducted in different geography whereas this particular study was conducted in some selective tertiary level government hospitals of Bangladesh where patients had to wait longer for operation (Talpur, K.A.H. et al., 2011).

\section{Costs of cholecystectomy}

Average treatment cost of the patients was slightly higher in laparoscopic group

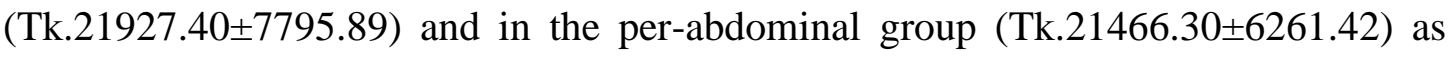
well as average direct cost and indirect cost of laparoscopic group of patients

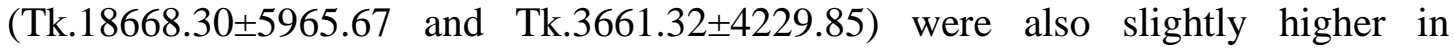
comparison to that of per-abdominal group of patients (Tk.18228.00 \pm 4624.75 and

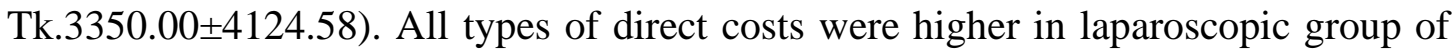
patients than in per-abdominal group except average hospital cost which was higher in the per-abdominal group (Tk.3851.67 \pm 2190.43 ) than in the laparoscopic group (Tk.3296.77 \pm 2215.14$)$. Among the different types of indirect costs, average income loss was Tk.5833.33( \pm 3685.56$)$ and Tk.5833.33( \pm 3356.59$)$ in per-abdominal and laparoscopic group of patients respectively which were similar to each other. But the average family cost was higher in per-abdominal group (Tk.6833.33 \pm 4242.64 ) than that in laparoscopic group (Tk.5885.71 \pm 4272.04$)$ while average cost for tips was higher in laparoscopic group (Tk.691.00 \pm 243.21 ) than that in per-abdominal group (Tk.672.22 \pm 185.19 ). No unofficial payment was given by the patients in perabdominal group whereas average unofficial payment in laparoscopic group was Tk.300.00( \pm 100.00$)$. This difference can be justified by the fact that laparoscopic cholecystectomy is costly than per-abdominal cholecystectomy. Each component of treatment cost was higher in laparoscopic than per-abdominal cholecystectomy except hospital cost. This was due to average duration of hospitalization was longer in perabdominal group than laparoscopic group. A study conducted in a private medical college hospital of Bangladesh where average operation cost was Btk.9920.00, medicine cost was Btk.8691.00 and total cost was Btk.22738.00 in laparoscopic group whereas average operation cost was Btk.8110.00, medicine cost was Btk.15091.00 and total cost was Btk.30685.00 in per-abdominal group. It showed that average total cost was higher in per-abdominal group than laparoscopic group (Rahman, M.S. et al., 
2016).

By sources of fund, among, 76.7\% patients in per-abdominal group and 85.0\% patients in laparoscopic group used family income while $46.7 \%$ patients in perabdominal group and $45.0 \%$ patients in laparoscopic group received loan from relatives for treatment. This difference can be justified by the facts that patients underwent laparoscopic cholecystectomy were economically solvent than patients underwent per-abdominal cholecystectomy. To cope up treatment costs about 50.0\% patients of per-abdominal group and $40.0 \%$ of laparoscopic group compromised with any basic needs of sufficient food provision and clothing, adequate shelter for residing, treatment of other family members, and education of family members etc. Among them, cost of food was compromised by $93.3 \%$ and $70.0 \%$ patients, cost of clothing was compromised by $73.3 \%$ and $45.8 \%$ patients and cost for treatment of other family members was compromised by $60.0 \%$ and $54.2 \%$ patients in perabdominal and laparoscopic group respectively. These differences were explained by the facts though laparoscopic cholecystectomy was costly than per-abdominal cholecystectomy but more patients of per-abdominal group compromised their basic needs as because average income of the patients in per-abdominal cholecystectomy group was less than that of laparoscopic group of patients.

\section{Cost-effectiveness of cholecystectomy}

The study revealed no association of age and sex of the patients with the cost of treatment in both per-abdominal group and laparoscopic group (Fisher's Exact, $\mathrm{p}>0.05$ ). The study didn't found any association of educational status, occupation and monthly family income of the patients with the cost of treatment in both perabdominal group and laparoscopic group (ANOVA, $p>0.05$ ). The study also didn't found any association of first place of diagnosis and place of treatment with the cost of treatment in both per-abdominal group and laparoscopic group (Fisher's Exact, $\mathrm{p}>0.05)$. In a previous study showed that the difference in projected 5- year cumulative charges between laparoscopic cholecystectomy and open cholecystectomy increases substantially with increasing age for both women and men (Bass, E.B., 1993). Another study reveled that there was no statistical difference between the two groups regarding age, sex distribution (Majbar, M.A. et al., 2015).

The study found a significant association between duration of cholelithiasis and cost of treatment in per-abdominal group as the cost increased among those who were 
suffering cholelithiasis for more duration (Fisher's Exact, $\mathrm{p}<0.05$ ), but in the laparoscopic group there was no association between duration of cholelithiasis and cost of treatment (Fisher's Exact, $\mathrm{p}>0.05$ ). The study didn't found any association between duration of hospitalization and cost of treatment in per-abdominal group (Fisher's Exact, $\mathrm{p}>0.05$ ), but in the laparoscopic group there was significant association between duration of hospitalization and cost of treatment as the cost increased among those who were hospitalized for more duration (Fisher's Exact, $\mathrm{p}<0.05)$. The study revealed that in per-abdominal group total treatment cost as well as direct and indirect cost significantly correlated with hospital stay (correlation, $\mathrm{p}<0.05)$ whereas in laparoscopic group both total treatment cost and direct cost significantly correlated with hospital stay (correlation, $\mathrm{p}<0.01$ ) but indirect cost didn't correlated with hospital stay. In a study conducted by Keus, F. et al. it was found that mean length of hospitalization was significantly higher compared to laparoscopic group (P 0.001) (Keus, F. et al., 2006).

Average treatment cost of the patients was slightly higher in laparoscopic group

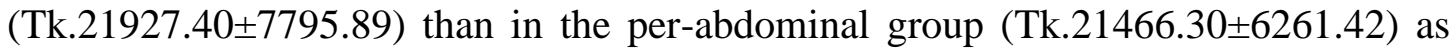
well as average direct cost and indirect cost of laparoscopic group of patients (Tk.18668.30 \pm 5965.67 and Tk.3661.32 \pm 4229.85 ) were also higher in comparison to

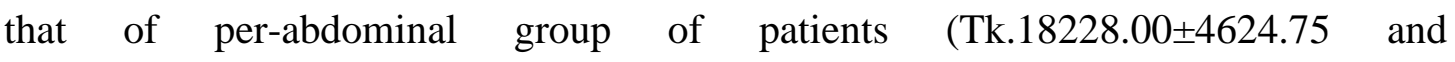

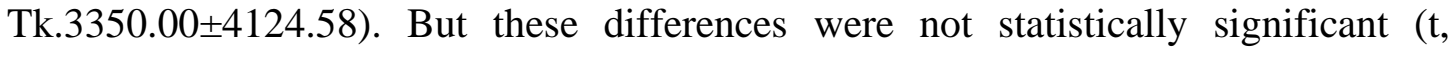
$\mathrm{p}>0.05)$. Relevant result were found in a study which showed that in Rwanda Military Hospital total costs were $\$ 2664.47$ and $\$ 2058.72$ respectively in laparoscopic and perabdominal cholecystectomy (Silverstein, A. et al., 2016).

These diversifications of costs can be explained by the facts that laparoscopic cholecystectomy little more costly in comparison to per-abdominal cholecystectomy. Moreover, average treatment cost was higher but not significant in laparoscopic group because patients underwent laparoscopy were more cautious about disease and spend more money for treatment. On the other hand, patients underwent per-abdominal cholecystectomy required comparatively less money for treatment but they required relatively longer hospital stay to recover which increased their average treatment cost but it was comparatively less than that of laparoscopic group patients.

Relevant result were found in a study which showed that in Rwanda Military Hospital total costs were $\$ 2664.47$ and $\$ 2058.72$ respectively in laparoscopic and perabdominal cholecystectomy (Silverstein, A. et al., 2016). Another study conducted in 
a medical college hospital, at Ahmednagar, Maharashtra, India revealed that average cost incurred in laparoscopic cholecystectomy about 11,500-12,500 rupees and in perabdominal cholecystectomy about 9,000-10,000 rupees (Doke, A. et al., 2016). A study conducted in a private medical college hospital of Bangladesh where average operation cost was Btk.9920.00, medicine cost was Btk.8691.00 and total cost was Btk.22738.00 in laparoscopic group whereas average operation cost was Btk.8110.00, medicine cost was Btk.15091.00 and total cost was Btk.30685.00 in per-abdominal group. It showed that average total cost was higher in per-abdominal group than laparoscopic group (Rahman, M.S. et al., 2016).

Significant difference was found in respect of outcome of cholecystectomy. More patients were cured in laparoscopic cholecystectomy group (94.4\%) than in perabdominal cholecystectomy group $(86.7 \%)\left(\chi^{2}, \mathrm{p}<0.05\right)$. Regarding outcome a previous study found that $11.5 \%$ patients developed complications where wound infections occurred $9.3 \%$ in the per-abdominal group and $1.8 \%$ in the laparoscopic group. There were statistically more infectious complications in the per-abdominal group ( $\mathrm{P}=0.04)$ (Majbar, M.A. et al., 2015). 


\section{Conclusion}

Cholecystectomy is the most commonly performed surgical procedure worldwide. It may be either per-abdominal or laparoscopic. Evaluation of cost-effectiveness of laparoscopic cholecystectomy in comparison to per-abdominal method from patients' perspective is a time demand. In this cross sectional study in two sample situations 90 patients (60 underwent $\mathrm{LC}$ and 30 underwent PAC) were interviewed during discharge from three tertiary level government hospitals of Dhaka, Bangladesh. In this study it was found that females were about three and half times more sufferer than males. The study also compared relevant background such as age, marital status, family history, education, occupation between per-abdominal and laparoscopic group but no significant difference was found. This particular study showed that rich patients were more likely done laparoscopic cholecystectomy. Patients suffering for cholelithiasis were nearly one year in both per-abdominal and laparoscopic group. It suggests that patients were unaware about their disease which creates economic load to them and their family. In per-abdominal group more than half of the patients were diagnosed at government hospitals whereas in laparoscopic group more than half of the patients were diagnosed at private hospitals. It was explained by the fact that patients underwent laparoscopy were rich than per-abdominal group. Average hospital stay was quite similar in both groups as because they had to wait longer for operation. Average treatment cost was similar in both groups. It was significant that higher percentage of patients cured in laparoscopic group than per-abdominal group. So, this particular study recommends that in patients perspective laparoscopic cholecystectomy is cost-effective than per-abdominal cholecystectomy in respect of lower rate of postoperative complications and shorter average hospital stay than perabdominal cholecystectomy. This study recommends motivation of the cholelithiasis patients for laparoscopy. 


\section{Recommendations}

$\square \square$ Laparoscopic cholecystectomy is cost-effective procedure than per-abdominal

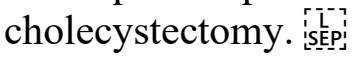

$\square \square$ To reduce the direct cost of cholecystectomy, minimization of hospital stay, reduction of unnecessary investigation, availability of treatment at door step should be

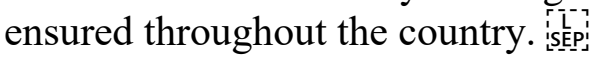

To reduce the indirect costs of cholecystectomy, security of income and reduction

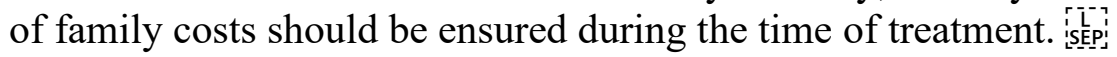

$\square \square$ To reduce total treatment costs of cholecystectomy, reduction of delay of time for diagnosis, need based laboratory investigation and treatment in government hospitals should be ensured throughout the country.

$\square$ Comprehensive study should be carried out broadly which will represent the country to determine the cost-effectiveness of laparoscopic procedure over perabdominal procedure. is is-pi] 


\section{References}

Aerts, R., Penninckx, F. (2003). The burden of gallstone disease in Europe. Alimentary Pharmacology \& Therapeutics. Vol.18, Suppl 3, pp.49-53.

Alkire, B.C., Raykar, N.P., Shrime, M.G., Weiser, T.G., Bickler, S.W., Rose, J.A., et al. (2015). Global access to surgical care: a modelling study. Lancet Global Health. Vol.3, No.(6), pp.316-323.

Anmol, N., Lakshminarayan, G., Manohar, T.M., Avadhani, G.K., Abinash, H. (2014). Outcome following open and laparoscopic cholecystectomy. Journal of Evolution of Medical and Dental Sciences. Vol.3, No.15, pp.4061-71.

Bailey, H.H., Dan, D.V. (2005). An economic evaluation of laparoscopic cholecystectomy for public hospitals in Trinidad and Tobago. West Indian Medical Journal. Vol.54, No.2, pp.110.

Bangladesh Bureau of Statistics, (2017). 2016 Statistical Year Book Bangladesh, 36th edition, Dhaka, Bangladesh. p.76.

Bass, E.B., Pitt, H.A., Lillemoe, K.D. (1993). Cost-Effectiveness of Laparoscopic Cholecystectomy Versus Open Cholecystectomy. The American Journal of Surgery. Vol.165, pp.466-71.

Boni, L., Benevento, A., Rovera, F., Dionigi, G., Di Giuseppe, M., Bertoglio, C., et al. (2006). Infective complications in Laparoscopic surgery. Surgical Infection Society (US). Vol.7, Supply 2, pp.109-11.

Carbajo, C.M., Martín, D.O.J., Blanco, A.J., Cuesta, D.L.L.C., Atienza, S.R., Inglada, G.L., et al. (1998). Surgical treatment of acute cholecystitis in the laparoscopic age. A comparative study: Laparoscopy against laparotomy: Revista Espanola De Enfermedades Digestivas. Vol.90, No.11, pp.788-93.

Cawich, S.O., Mitchell, D.I., Newnham, M.S., Arthurs, M. (2006). A comparison of open and laparoscopic cholecystectomy done by a surgeon in training. West Indian Medical Journal, Vol.55, No.2, pp.103-9.

Chao, T.E., Sharma, K., Mandigo, M., Hagander, L., Resch, S.C., Weiser, T.G., et al. (2014). Cost-effectiveness of surgery and its policy implications for global health: a 
systematic review and analysis. Lancet Global Health. Vol.2, pp.e334-e345.

Chau, C.H., Siu, W.T., Tang, C.N., Ha, P.Y., Kwok, S.Y., Yau, K.K. et al. (2006). Laparoscopic cholecystectomy for acute cholecystitis: the evolving trend in an institution. Asian Journal of Surgery. Vol.29, No.3, pp.120-4.

Choy, I., Kitto, S., Adu-Aryee, N., Okrainec, A. (2013). Barriers to the uptake of laparoscopic surgery in a lower-middle-income country. Surgical Endoscopy, Vol.27, No.11, pp.4009-15.

Chuang, S.C., Lee, K.T., Chang, W.T., Wang, S.N., Kuo, K.K., Chen, J.S., et al. (2004). Risk factors for wound infection after cholecystectomy. Journal of the Formosan Medical Association. Vol.103, No.8, pp.607-12.

Coccolini, F., Catena, F., Pisano, M., Gheza, F., Fagiuoli, S., Di Saverio, S., et al. (2015). Open versus laparoscopic cholecystectomy in acute cholecystitis- Systematic review and meta-analysis. International Journal of Surgery. Vol.18, pp.196-204.

Conlon, K. (2008). The gallbladder and bile ducts. In: Russel, R.C.G., Williams, N.S., Bulstrode, C.J.K. (eds.). Baily and loves short practice of surgery, 25th ed. Edward Arnold (Publishers) Ltd, London. Vol.2, pp.1119.

Costi, R., Gnocchi, A., Di Mario, F., Sarli, L. (2014). Diagnosis and management of choledocholithiasis in the golden age of imaging, endoscopy and laparoscopy. World Journal Gastroenterology. Vol.20, No.37, pp.13382-401.

Cuschieri, A.S. (2002). Disorders of biliary tree. In: Cuschieri, A.S., Steele, R.J.C., Moosa, A.R. (eds.). Essential. Surgical Practice, 4th ed, Arnold Euston Road London NW. 13 BH;II(I), pp.406.

Dasari, B.V.M., Tan, C.J., Gurusamy, K.S., Martin, D.J., Kirk, G., McKie, L., et al. (2013). Surgical versus endoscopic treatment of bile duct stones. The Cochrane Database of Systematic Reviews. Vol.12, pp.CD003327.

Demoulin, L., Kesteloot, K., Penninckx, F. (1996). A cost comparison of disposable vs reusable instruments in laparoscopic cholecystectomy. Surgical Endoscopy. Vol.10, pp.520-5.

Doke, A., Gadekar, N., Gadekar, J., Dash, N., Unawane, S. (2016). A comparative 
study between open versus laparoscopic cholecystectomy. Scholars Journal of Applied Medical Sciences. Vol.4, No.1A, pp.57-61.

Dolan, J.P., Diggs, B.S., Sheppard, B.C., Hunter, J.G. (2009). The national mortality burden and significant factors associated with open and laparoscopic cholecystectomy: 1997-2006. Journal of Gastrointestinal Surgery. Vol.13, No.12, pp.2292-301.

Drummond, M.F., Sculpher, M.J., Torrance, G.W., O'Brien, B.J., Stoddart, G.L. (eds.) (2005). Methods for the economic evaluation of health care programme. Third edition. Oxford: Oxford University Press.

El-Fellah, N., Rogdakis, A., Giannakakis , P., Karambas, V., Gratsias, G., Bouras, P., et al. (2011). Cost of laparosopic and open cholecystectomy in a general hospital from the point of view of health care budgeting. Hellenic Journal of Surgery. Vol.83, No.3, pp.139-147.

Everhart, J.E., Yeh, F., Lee, E.T., Hill, M.C., Fabsitz, R., Howard, B.V., et al. (2002). Prevalence of gallbladder disease in American Indian populations: findings from the Strong Heart Study. Hepatology. Vol.35, No.6, pp.1507-12.

Fajardo, R., Valenzuela, J.I., Olaya, S.C., Quintero, G., Carrasquilla, G., Pinzón, C.E., et al. (2011). Cost-effectiveness of laparoscopic versus open cholecystectomy. Biomedica, Vol.31, No.4, pp.514-24.

Fletcher, D.R., Hobbs, M.S., Tan, P., Valinsky, L.J., Hockey, R.L., Pikora, T.J., et al. (1999). Complications of cholecystectomy: risks of the laparoscopic approach and protective effects of operative cholangiography: a population-based study. Annals of Surgery. Vol.229, No.4, pp.449-57.

Ford, J.A., Soop, M., Du, J., Loveday, B.P.T., Rodgers, M. (2012). Systematic review of intraoperative cholangiography in cholecystectomy. British Journal of Surgery. Vol.99, No.2, pp.160-7.

Fullarton, G.M., Darling, K., Williams, J., MacDillan, R., Bell, G. (1994). Evaluation of the cost of laparoscopic and open cholecystectomy. British Journal of Surgery. Vol.81, pp.124-6.

Glasgow, R.E., Mulvihill, S.J. (2010). Treatment of gallstone disease. In: Feldman, 
M. et al. (eds.), Sleisenger and Fordtran's Gastrointestinal and Liver Disease, 9th ed., Philadelphia: Saunders. Vol.1, pp.1121-1138.

Gurusamy, K.S., Vaughan, J., Rossi, M., Davidson, B.R. (2014). Fewer than four ports versus four ports for laparoscopic cholecystectomy. The Cochrane Database of Systematic Reviews. Vol.2, pp.CD007109.

Harrison, E.M., O’Neill, S., Meurs, T.S., Wong, P.L., Duxbury, M., Paterson-Brown, S., et al. (2012). Hospital volume and patient outcomes after cholecystectomy in Scotland: retrospective, national population based study.British Medical Journal. Vol.344, pp.e3330.

Hosseini, S.N., Mousavinasab, S.N., Rahmanpour, H., Vakili, M.M. (2008). A comparison of the outcome between acute open and acute laparoscopic cholecystectomy. Iranian Red Crescent Medical Journal. Vol.10, No.2, pp.84-88.

Jackson, H., Granger, S., Price, R., Rollins, M., Earle, D., Richardson, W., et al. (2008). Diagnosis and laparoscopic treatment of surgical diseases during pregnancy: an evidence-based review. Surgical Endoscopy. Vol.22, No.9, pp.1917-27.

Jatzko, G.R., Lisborg, P.H., Pertl, A.M., Stettner, H.M. (1995). Multivariate Comparison of Complications After Laparoscopic Cholecystectomy and Open Cholecystectomy. Annals of Surgery. Vol.221, No.4, pp.381-386.

Jirsa, M., Groen, A.K. (2001). Role of biliary proteins and nonOprotein factors in kinetics of cholesterol crystallisation and gallstone growth. Frontiers in Bioscience. Vol.6, pp.E154-67.

Johansson, M., Thune, A., Nelvin, L., Stiernstan, M., Westman, B., Lundell, L. (2005). Randomized clinical trial of open versus laparoscopic cholecystectomy in the treatment of acute cholecystitis. British Journal of Surgery. Vol.92, No.1, pp.44-49.

Johnston, D.E., Kaplan, M.M. (1993). Pathogenesis and treatment of gallstones. The New England Journal of Medicine.Vol.328, No.25, pp.412-21.

Kaafarani, H.M., Smith, T.S., Neumayer, L., Berger, D.H., Depalma, R.G., Itani, K.M.F. (2010). Trends, outcomes, and predictors of open and conversion to open cholecystectomy in Veterans Health Administration hospitals. The American Journal of Surgery. Vol.200, No.1, pp.32-40. 
Keus, F., de Jong, J.A., Gooszen, H.G., van Laarhoven, C.J. (2006). Laparoscopic versus small incision cholecystectomy for patients with symptomatic cholecystolithiasis. The Cochrane Database of Systematic Reviews. Vol.18, No.4, pp.CD006229.

Konikoff, F.M., Danino, D., Weihs, D., Rubin, M., Talmon, Y. (2000). Microstructural evolution of lipid aggregates in nucleating model and human biles visualized by cryogenic transmission electron microscopy. Hepatology. Vol.31, No.2, pp.261-8.

Kramp, K.H., van Det, M.J., Totte, E.R., Hoff, C., Pierie, J.P. (2014). Ergonomic assessment of the French and American position for laparoscopic cholecystectomy in the MIS Suite. Surgical Endoscopy. Vol.28, No.5, pp.1571-8.

Langenbuch, C. (1882). Ein Fall von Extirpation der Gallenblase wegen chronischer Cholelithiasis: Heilung. Berliner Klin Wochenschr. vol.19, pp.725-7.

Livingstone, E.H., Rege, R.V. (2004). A nationwide study of conversion from Laparoscopic to open cholecystectomy. The American Journal of Surgery. Vol.188, pp.205-211.

Lundberg, O., Kristoffersson, A. (2001). Per-abdominal versus laparoscopic cholecystectomy for gallbladder carcinoma. Journal of Hepato-Biliary-Pancreatic Surgery. Vol.8, No.6, pp.525-9.

Luschka, H.V., Oddi, R., Vater, A., Moynihan, B.G.A. (2008). Bailey \& Love's Short practice of surgery. 25 ed. London: Edward Arnold (Publishers) Ltd. pp.1123-24.

Maitra, T.K., Ullah, M.E., Faruquzzaman, Mondol S.K. (2017). Operative and Postoperative Complications of Laparoscopic Cholecystectomy: Experience from a Tertiary Care Hospital of Bangladesh. Bangladesh Critical Care Journal. Vol.5, No.1, pp.11-16.

Majbar, M.A., Benkabbou, A., Souadka, A. (2015). Comparison of Early Outcomes and Costs between Laparoscopic and Open Cholecystectomy for Mild and Moderate Cases of Cholelithiasis in Rural Morocco: A Retrospective Comparative Study. Journal of Minimally Invasive Surgical Sciences. Vol.4, No.4, p.e34182. 
Manning, R.G., Aziz, A.Q. (2009). Should laparoscopic cholecystectomy be practiced in the developing world?: the experience of the first training program in Afghanistan. Annals of Surgery. Vol.249, No.5, pp.794-8.

Meara, J.G., Leather, A.J.M., Hagander, L., Alkire, B.C., Alonso, N., Ameh, E.A., et al., (2015). Global Surgery 2030: evidence and solutions for achieving health, welfare, and economic development. Lancet. Vol.386, No.9993, pp.569-624.

Medeiros, A.C., Araújo-Filho, I., Carvalho, M.D.F., Medeiros, V.F.L.P., Azevedo, Í.M., Filho, A.M.D. (2012). Laparoscopic versus open cholecystectomy: complications and cost. Journal of Surgical and Clinical Research. Vol.3, No.2, pp.4958.

Morgenstern, L., Wong, L., Berco, G. (1992). Twelve hundred open cholecystectomies before the laparascopic era. A standard for comparison. Archives of Surgery. Vol.127, pp.400-403.

Muhe, E. (1986). Die erste cholecystektomie durch das laparoskop. Langenbecks Arch Klin Chir. vol.369, pp.804.

Naeem, M., Rahimnajjad, N.A., Rahimnajjad, M.K., Khurshid, M., Ahmed, Q.J., Shahid, S.M., et al. (2012). Assessment of characteristics of patients with cholelithiasis from economically deprived rural Karachi, Pakistan. Bio-Med Central Research Notes. Vol.5, p.334.

Nuzzo, G., Giuliante, F., Giovannini, I., Ardito, F., D’Acapito, F., Vellone, M., et al. (2005). Bile duct injury during laparoscopic cholecystectomy: results of an Italian national survey on 56591 cholecystectomies. American Medical Association Archives of Surgery. Vol.140, No.10, pp.986-92.

O’Connell, K., Brasel, K. (2014). Bile metabolism and lithogenesis. Surgical Clinics of North America. Vol.94, No.2, pp.361-75.

Overby, D.W., Apelgren, K.N., Richardson, W., Fanelli, R. (2010). SAGES guidelines for the clinical application of laparoscopic biliary tract surgery. Surgical Endoscopy. Vol.24, No.10, pp.2368-86.

Patrick, J.J.,David, C.B. (2004). Cholecystectomy. in: Johnson, L. (ed.) Encyclopedia of Gastroenterology. Elsevier (USA), pp.317-321. 
Pessaux, P., Regenet, N., Tuech, J.J., Rouge, C., Bergamaschi, R., Arnaud, J.P. (2001). Laparoscopic versus open cholecystectomy: a prospective comparative study in the elderly with acute cholecystitis. Surgical Laparoscopy Endoscopy \& Percutaneous Techniques. Vol.11, pp.252-5.

Peters, D.H., Yazbeck, S.A., Sharma, R.R., Ramana, G.N.V., Pritchett, H.L., Wagstaff, A. (2002). Better Health Systems for India's Poor: Findings, Analysis, and Options. Washington, DC, World Bank.

Price, R., Sergelen, O., Unursaikhan, C. (2013). Improving surgical care in Mongolia: a model for sustainable development. World Journal of Surgery, Vol.37, pp.14921499.

Rahman, M.S., Islam, S.M.R., Pasha, K., Chowdhury, M.R.A., Paul, D., Saad, S. (2016). Cost Effective Cholecystectemy in A Rural Tertiary Care Hospital. Anwer Khan Modern Medical College Journal. Vol.7, No.1, pp.20-22.

Rai, M.A., Aslam, M.F., Aslam, S. (2014). Laparoscopic Cholecystectomy - Outcome and Complications. Journal of Rawalpindi Medical College. Vol.18, No.2, pp.234236.

Ray-Offor, E., Okoro, P.E., Gbobo, I., Allison, A.B. (2014). Pilot study on laparoscopic surgery in Port-Harvourt, Nigeria. Nigerian Journal of Surgery. Vol.20, No.1, pp.23-25.

Rohatgi, A., Widdison, A.L. (2006). An audit of cystic duct closure in laparoscopic cholecystectomies. Surgical Endoscopy. Vol.20, No.6, pp.875-7.

Ros, A., Carlsson, P., Rahmqvist, M., Bachman, K., Nilsson, E. (2006). Nonrandomised patients in a cholecystectomy trial characteristics, procedures and outcomes. BioMed Central Surgery. Vol.6, pp.17.

Saia, M., Mantoan, D., Buja, A., Bertoncello, C., Baldovin, T., Callegaro, G., et al., (2013). Time trend and variability of open versus laparoscopic cholecystectomy in patients with symptomatic gallstone disease. Surgical Endoscopy. Vol.27, No.9, pp.3254-61.

Sakorafas, G.H., Milingos, D., Peros, G. (2007). Asymptomatic cholelithiasis: is cholecystectomy really needed? A critical reappraisal 15 years after the introduction 
of laparoscopic cholecystectomy. Digestive Diseases and Sciences. Vol.52, No.5, pp.1313-25.

Sandblom, G., Videhult, P., Crona Guterstam, Y., Svenner, A., \& Sadr-Azodi, O. (2015). Mortality after a cholecystectomy: a population-based study. HPB : The Official Journal of the International Hepato Pancreato Biliary Association. Vol.17, No.3, pp.239-243.

Shaffer, E.A. (2006). Gallstone disease: epidemiology of gallbladder stone disease. Best Practice \& Research, Clinical Gastroenterology. Vol.20, pp.981-996.

Shamiyeh, A., Wanyand, W. (2004). Laparoscopic cholecystectomy: early and late complication and their treatment, Langenbeck's Archives of Surgery. Vol.389, pp.164- 71 .

Shrime, M.G., Dare, A.J., Alkire, B.C., O'Neill, K., Meara, J.G. (2015). Catastrophic expenditure to pay for surgery: a modelling study. The Lancet Global Health, Vol.3, pp.38-44.

Shukla, A., Seth, S., Ranjan, A. (2017). A comparative study between laparoscopic and open cholecystectomy in cases of cholecystitis with cholelithiasis: one year experience in tertiary care center. International Surgery Journal. Vol.4, pp.903-7.

Silverstein, A., Costas-Chavarri, A., Gakwaya, M.R., Lule, J., Mukhopadhyay, S., Meara, J.G., et al. (2016). Laparoscopic Versus Open Cholecystectomy: A CostEffectiveness Analysis at Rwanda Military Hospital. World Journal of Surgery. Vol.41, No.5, pp.1225-1233.

Solanki, K., Parmar, H., Gohil, V., Shah, S. (2010). Comparative study between open v/s laparoscopic cholecystectomy. National Journal of Integrated Research in Medicine. Vol.1, No.1, pp.18-20.

Soper, N.J., Stockmann, P.T., Dunnegan, D.L., Ashley, S.W. (1992). Laparoscopic cholecystectomy. The new 'gold standard'? Archives of Surgery. Vol.127, No.8, pp.917-23.

Stevens, H.P., van de Berg, M., Ruseler, C.H., Wereldsma, J.C. (1997). Clinical and financial aspects of cholecystectomy. Laparoscopic versus open technique. World Journal of Surgery. Vol.21, No.1, pp.91-6. 
Stoker, M.E., Vose, J., O’Mara, P., Maini, B.S. (1992). Laparoscopic cholecystectomy. A clinical and financial analysis of 280 operations. Archives of Surgery. Vol.127, pp589-595.

Syrakos, T., Antonitsis, P., Zacharakis, E., Takis, A., Manuousari, A., Bakogiannis, K., et al. (2004). Small incision (Mini-Laparotomy) versus laparoscopic cholecystectomy: A retrospective study in a University Hospital. Langenbeck's Archives of Surgery. Vol.389, No.3, pp.172-177.

Talpur, K.A.H., Malik, A.M., Sangrasi, A.K., Memon, A.I., Leghari, A.Z., Qureshi, J.N. (2011). Comparative study of conventional open versus laparoscopic cholecystectomy for symptomatic cholelithiasis. Pakistan Journal of Medical Sciences. Vol.27, No.1, pp.33-37.

Teixeira, J.A., Ribeiro, C., Moreira, L.M., de Sousa, F., Pinho, A., Graça, L., et al. (2014). Laparoscopic cholecystectomy and open cholecystectomy in acute cholecystitis, Acta Medica Portuguesa. Vol.27, No.6, pp.685-691.

Tiwari, M.M., Reynoso, J.F., High, R., Tsang, A.W., Oleynikov, D. (2011) Safety, efficacy, and cost-effectiveness of common laparoscopic procedures. Surgical Endoscopy. Vol.25, No.4, pp.1127-1135.

Tzovaras, G., Dernvenis, C. (2006). Vascular injuries in laparoscopic cholecystectomy: an underestimated problem. Digestive Surgery, Vol.23, No.5-6, pp.370-4.

Visser, B.C., Parks, R.W., Garden, O.J. (2008). Open cholecystectomy in the laparoendoscopic era. The American Journal of Surgery. Vol.195, No.1, pp.108-14.

Volzke, H., Baumeister, S.E., Alte, D., Hoffmann, W., Schwahn, C., Simon, P., et al. (2005). Independent risk factors for gallstone formation in a region with high cholilithiasis prevalence. Digestion. Vol.71, No.2, pp.97-105.

Wenner, D.E., Whitwam, P., Turner, D., Chadha, A., Degani, J. (2006). Laparoscopic cholecystectomy and management of biliary tract stones in a freestanding ambulatory surgery center. Journal of the Society of Laparoendoscopic Surgeons. Vol.10, pp.4751.

Wolf, A.S., Nijsse, B.A., Sokal, S.M., Chang, Y., Berger, D.L. (2009). Surgical 
outcomes of open cholecystectomy in the laparoscopic era. American Journal of Surgery. Vol.197, No.6, pp.781-4.

Zacks, S.L., Sandler, R.S., Rutledge, R., Brown, R.S. (2002). A populationObased cohort study comparing laparoscopic cholecystectomy and open cholecystectomy. The American Journal of Gastroenterology. Vol.97, No.2, pp.334-40. 